\title{
Investigation of ULF magnetic pulsations, air conductivity changes, and infra red signatures associated with the 30 October Alum Rock M5.4 earthquake
}

\author{
T. Bleier ${ }^{1}$, C. Dunson ${ }^{1}$, M. Maniscalco ${ }^{1}$, N. Bryant ${ }^{2}$, R. Bambery ${ }^{2}$, and F. Freund ${ }^{3}$ \\ ${ }^{1}$ QuakeFinder Inc., Palo Alto, California 94306, USA \\ ${ }^{2}$ NASA Jet Propulsion Laboratory (JPL), Pasadena, California 91109, USA \\ ${ }^{3}$ NASA Ames Research Center, Moffett Field, California 94035, USA
}

Received: 11 September 2008 - Revised: 9 March 2009 - Accepted: 11 March 2009 - Published: 16 April 2009

\begin{abstract}
Several electromagnetic signal types were observed prior to and immediately after 30 October 2007 (Local Time) M5.4 earthquake at Alum Rock, Ca with an epicenter $\sim 15 \mathrm{~km}$ NE of San Jose Ca. The area where this event occurred had been monitored since November 2005 by a QuakeFinder magnetometer site, unit $609,2 \mathrm{~km}$ from the epicenter. This instrument is one of 53 stations of the QuakeFinder (QF) California Magnetometer NetworkCalMagNet. This station included an ultra low frequency (ULF) 3-axis induction magnetometer, a simple air conductivity sensor to measure relative airborne ion concentrations, and a geophone to identify the arrival of the P-wave from an earthquake. Similar in frequency content to the increased ULF activity reported two weeks prior to the Loma Prieta M7.0 quake in 1989 (Fraser-Smith, 1990, 1991), the QF station detected activity in the $0.01-12 \mathrm{~Hz}$ bands, but it consisted of an increasing number of short duration (1 to $30 \mathrm{~s}$ duration) pulsations. The pulsations peaked around 13 days prior to the event. The amplitudes of the pulses were strong, (3-20 nT), compared to the average ambient noise at the site, (10-250 pT), which included a component arising from the Bay Area Rapid Transit (BART) operations. The QF station also detected different pulse shapes, e.g. negative or positive only polarity, with some pulses including a combination of positive and negative. Typical pulse counts over the previous year ranged from $0-15$ per day, while the count rose to 176 (east-west channel) on 17 October, 13 days prior to the quake. The air conductivity sensor saturated for over $14 \mathrm{~h}$ during the night and morning prior to the quake, which occurred at 20:29 LT. Anomalous IR signatures were also
\end{abstract}

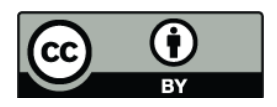

Correspondence to: T. Bleier (tbleier@quakefinder.com) observed in the general area, within $50 \mathrm{~km}$ of the epicenter, during the 2 weeks prior to the quake. These three simultaneous EM phenomena were compared with data collected over a 1-2-year period at the site. The data was also compared against accounts of air ionization reported to be associated with radon emission from the ground (Ouzounov, 2007), and a series of laboratory rock stressing experiments (Freund, $2006,2007 \mathrm{a}, \mathrm{b}, \mathrm{c})$ to determine if field data was consistent either of these accounts. We could not find a data set with preearthquake radon measurements taken near the Alum Rock epicenter to compare against our field data. However, based on the Alum Rock data set example and another data set at Parkfield, the field tests are at least consistent with the lab experiments showing currents, magnetic field disturbances, air conductivity changes, and IR signatures. This is encouraging, but more instrumented earthquake examples are needed to prove a repeating pattern for these types of pre-earthquake EM signatures.

\section{Introduction}

There have been many papers from the 1960's to present which reported electromagnetic signals prior to large earthquakes, These signals span the electromagnetic spectrum from slow moving DC magnetic field changes (Yen, 2004), ultra low frequency (ULF) magnetic field energy bursts (Fraser Smith, 2002; Molchanov, 2003, 2004), radio frequency signals from $\mathrm{kHz}$ to $\mathrm{MHz}$ (Fujinawa, 1990), infra red (IR) signatures (Ouzounov, 2007), visible earthquake lights (Derr, 1973), ionospheric disturbances (Pulinets, 2004; Molchanov, 2003, 2004; Liu, 2001, 2004), and others. Most of these phenomena are difficult to monitor in both space and

Published by Copernicus Publications on behalf of the European Geosciences Union. 
time due to the lack of sufficient instrumentation to cover large areas, and due to the large amounts of data required to be collected before infrequent earthquakes. Signatures collected using other parts of the EM spectrum (e.g. ULF, $\mathrm{kHz}, \mathrm{IR}$, etc.) are often contaminated with noise from cosmic, magnetospheric, anthropogenic or weather sources. Although these signals are interesting, the challenge is to determine if the signals correlate to specific earthquake preparation processes. This paper reports on a specific subset of the EM spectrum and the corresponding data sets collected for 30 October 2007 M5.4 Alum Rock earthquake. This paper looks for both temporal and spatial correlations between a medium strength earthquake, and ULF magnetic signals, IR signatures, and air conductivity changes. It further examines these signatures in the context of a recent theory of pre-earthquake processes. One theory (Freund, 2006, 2007a, $\mathrm{b}, \mathrm{c}$ ) involves the generation of $\mathrm{p}$-hole charge carriers during asymmetric rock stress, and the resulting underground currents and ULF magnetic fields. The theory also addresses the migration of the charge carriers to the surface where they change the local surface air conductivity and may create apparent IR heating signatures as observed by satellite instruments during the earthquake preparation process. Another theory (Ouzounov, 2007) addresses the potential release of radon near epicenters, the subsequent ionization of local air molecules, and corresponding capture of water vapor and eventual release of latent heat (IR). This paper cannot conclusively prove that all these phenomena occur prior to all or even most large earthquakes (since the data is primarily from a single event), but simply strives to determine if the data collected is consistent with either of these theories. Also, since electromagnetic noise contamination is so prevalent in the field data, this paper also investigates potential noise sources in each data set to determine if the data collected can be legitimately attributed to geophysical sources (e.g. earthquake processes), or could they be contaminated by extraneous electromagnetic noise sources (e.g. man-made fields, lightning, solar storms, etc.).

\section{Background}

Fraser-Smith (1990, 1991) collected ULF data near Corralitos, Ca prior to the 1989 Loma Prieta earthquake, and detected a $20 \times$ increase of ULF energy in several bands, with the maximum signal contained in the 0.01-0.022 band, 14 days prior to the quake. The data were processed and saved to $30 \mathrm{~min}$ averages to record the average signal intensity for each of 18 filter bands. The raw data was not saved due to storage constraints, and as a result, it is impossible to determine the exact nature of the signal structure and dynamics.

Other ULF signatures have been recorded, but some like the Chi-Chi earthquake (Yen, 2004) in Taiwan, used DC magnetometers. These signatures were hampered by slow sampling, and therefore lost some of the higher frequency signal components. QuakeFinder started building and deploying ULF magnetometers in 2000, and now have 53 three axis instruments deployed throughout California in the CalMagNet (Cutler, 2008). Twenty-five of these instruments also include simple air conductivity sensors, and collect and store 32 SPS of raw data in each of 5 data channels (3 magnetometers, a geophone, and air conductivity) using GPS as a time reference. These multiple station locations and GPScorrelated time finally allow us to compare data in space and time, both near and far from significant California earthquakes.

\section{Alum Rock quake}

The Alum Rock M5.4 Alum Rock quake occurred at 03:04:54 UTC on 31 October 2007 (20:04:54, 30 October local) located near the Calaveras fault at $37.432^{\circ} \mathrm{N}$, $121.776^{\circ} \mathrm{W}$, and its depth was $9.2 \mathrm{~km}$. QuakeFinder's QF1005 magnetometer sensor (unit 609) was located $2 \mathrm{~km} \mathrm{SW}$ of the epicenter, and that site's data had over two years of historical signal history. The raw data was collected with an instrument that used a $12 \mathrm{~Hz}$ low pass hardware filter in the instrument electronics, and the spectrogram was then generated using a Blackman window, 1024 FFT samples with a 16 factor overlap resulting in 513 frequency bins. Figure 1a is a sample of the daily data where pulsations (sharp vertical energy bands) were evident closer in time to the earthquake. This frequency spectrogram illustrated that the signals were observed in all three channels, and that the pulsations contained energy throughout the $5 \mathrm{~Hz}$ bandwidth. These pulsations were not part of the midnight and noon time calibrations signals $(0.8 \mathrm{~Hz}$ for $5 \mathrm{~min}$ in duration) that are injected into the magnetometers each day.

Figure $1 \mathrm{~b}$ illustrates a more detailed view of the DC to $0.16 \mathrm{~Hz}$ portion of the band, and particularly shows some energy in the $0.01 \mathrm{~Hz}$ band (orange horizontal energy band) where energy had been identified in the 1989 Loma Prieta earthquake (Fraser-Smith, 1990). Even more evident was the strong vertical pulsation signatures which had significant lower frequency energy content (vertical red bands).

One major question was whether these pulsations were observed at all sites (caused by global magnetospheric pulsations), or just detected at the site near the earthquake? Figure $1 \mathrm{c}$ shows a $2 \mathrm{~h}$ comparison of ULF time series data across the entire State of California. One can observe large pulses in the line labeled E. Milpitas which was $2 \mathrm{~km}$ from the epicenter. This early time period in the figure was also selected to show the BART train noise that typically starts around 3 a.m. each day. The BART noise can be clearly seen at the two sites (E. Milpitas and Portola Valley) which are in the Bay Area, at approximately 5-15 miles from the BART tracks respectively. The subject pulsations are much larger than these normal BART transients, and the pulsations appear to be unique 

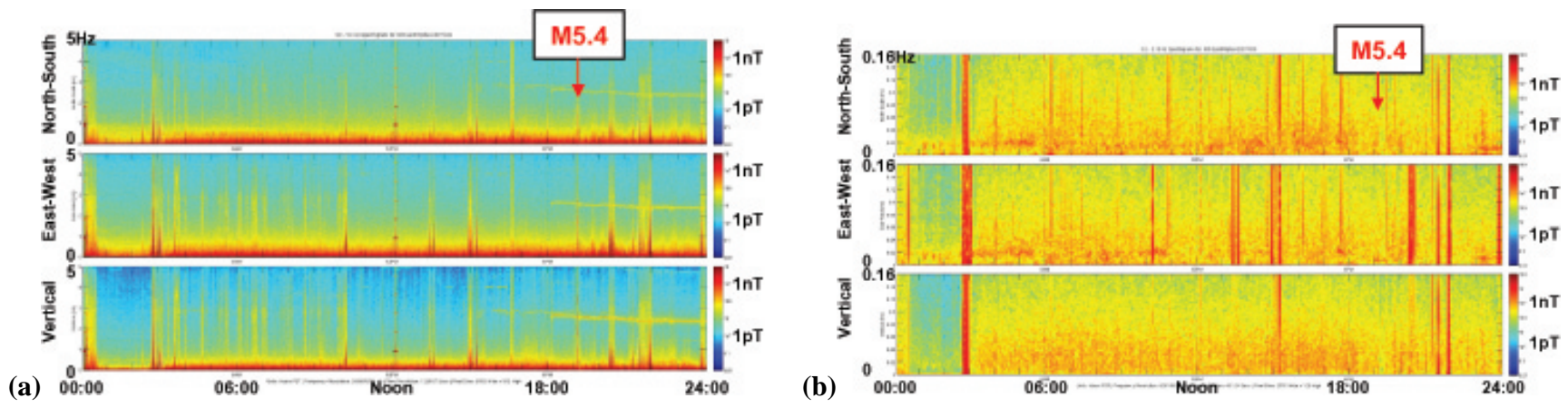

Network Wide Comparisons using Filter Band MA7

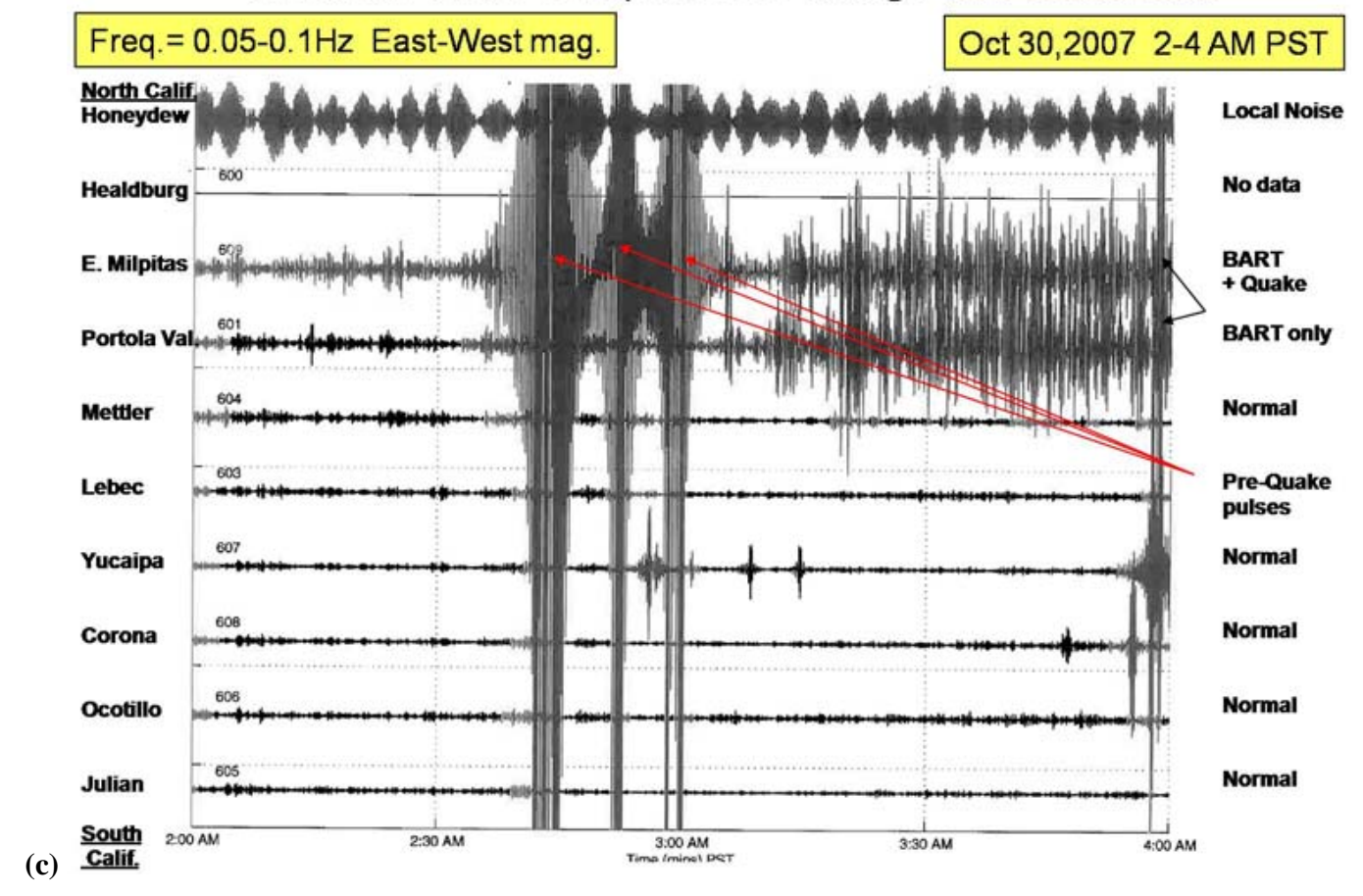

Fig. 1. (a) 24-h spectrogram display with north-south (top), east west (middle) and vertical magnetometer channel (bottom), frequency selected via software from $0.01 \mathrm{~Hz}$ to $5 \mathrm{~Hz}$ to display more low frequency detail. (b) 24-h spectrogram display with north-south (top), east west (middle) and vertical magnetometer channel (bottom), frequency selected via software from $0.01 \mathrm{~Hz}$ to $0.16 \mathrm{~Hz}$ to display more low frequency detail. (c) Two hour time slice of the $0.05-0.1 \mathrm{~Hz}$ Band time series plot comparison of all ten, high resolution, CalMagNet sites from Honeydew, Ca. (near Eureka, Ca), to Julian, Ca (east of San Diego, Ca).

to the East Milpitas, that is, they cannot be observed even at the closest site across the Bay, the Portola Valley site which is $30 \mathrm{~km}$ west of the epicenter. The noise on the top line (Healdsburg) is local machinery noise.

The specific site at E. Milpitas, near the epicenter, was analyzed, and a "normal" day (1 October 2007 in Fig. 2a) was compared to an "active day" (17 October 2007 in Fig. 2b) when there was considerable pulsation activity. Figure $2 \mathrm{a}$ illustrates the additional BART noise that can be seen all day, except between 1 a.m. and 3 a.m. when BART shuts down for maintenance. Figure $2 \mathrm{~b}$ illustrates the same East West channel for 17 October 2007 when the pulsations increased in occurrence. Note the vertical scale has changed and the calibrations signal $(0.8 \mathrm{~Hz}$ sine wave for $5 \mathrm{~min})$ ap- pears smaller, but are in fact, the same $8 \mathrm{nT}$ peak-to-peak cal. signals. There were significant pulsations just after midnight, as well as throughout the day at approximately 04:00, 08:00, 14:00, 19:00, and 22-24:00. Figure $2 \mathrm{c}$ is a $24 \mathrm{~h}$ time series for the day of the earthquake (30 October 2007). There is a co-seismic signal evident when the coils shake during the $\mathrm{P}$ and $\mathrm{S}$ wave sequence at 20:04 local time (arrow), but the time series continued to show large impulses into the following night. The ellipse again highlights the area in the middle of the night where historically, the instrument site is usually very quiet, but this night, there were large pulsations. Figure $2 \mathrm{~d}$ is that same night time data around 02:30, expanded to show the nature of the pulses including their unique polarity structures (positive only, negative only, and regular bi-polar 


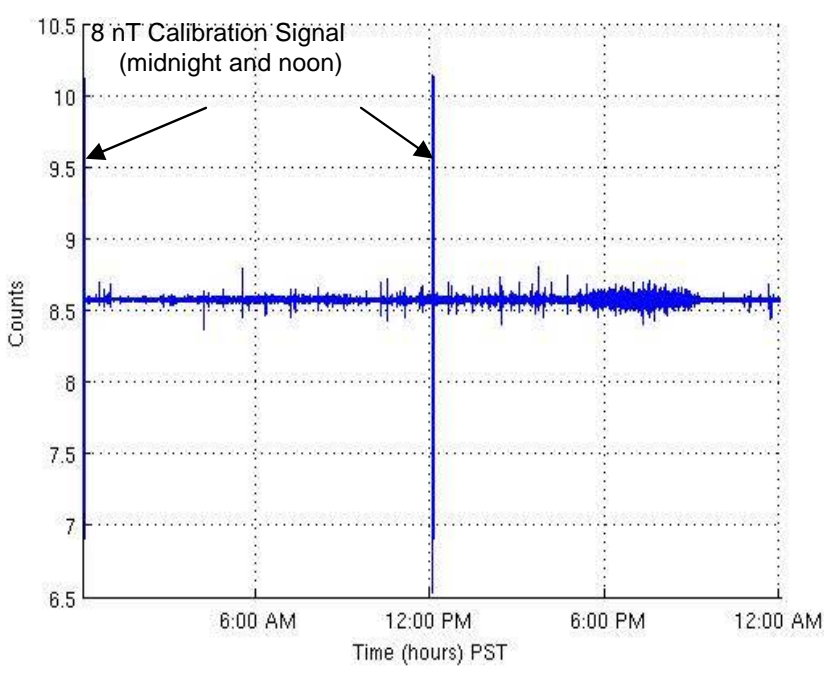

Fig. 2a. Time series E-W - quiet day (1 October).

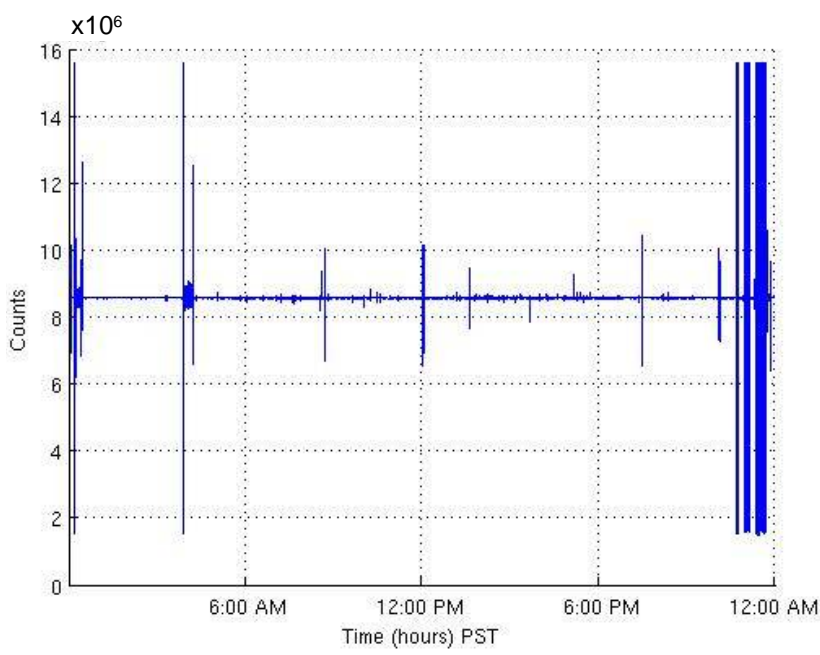

Fig. 2b. Time Series E-W - active day (17 October).

pulses). This instrument is an induction (AC) magnetometer, and therefore only changes in the local magnetic field are detected. The magnetic pulsations were also observed to be rather long $(8 \mathrm{~s}, 15 \mathrm{~s}, 15 \mathrm{~s})$ within this $183 \mathrm{~s}$ segment of time. These longer pulsation times are quite different when compared to local lightning ( 0.1 to $0.5 \mathrm{~s}$ ).

Every site has a characteristic local noise environment. As such, the site-specific area "background noise" was measured, and twice the largest noise signatures typically observed each day at each site was used as a "threshold level" to identify these unusual pulses. These pulse excursions were subsequently counted to quantify the rate of occurrence each day. Figure 3 illustrates a $24 \mathrm{~h}$ time series of one day, the day of earthquake at E. Milpitas, and the box in the lower left summarizes the pulses types and pulse counts for each type. Pulses above or below these threshold levels $\left(8.9 \times 10^{6}\right.$ counts for upper limit, and below $8.2 \times 10^{6}$ counts for the

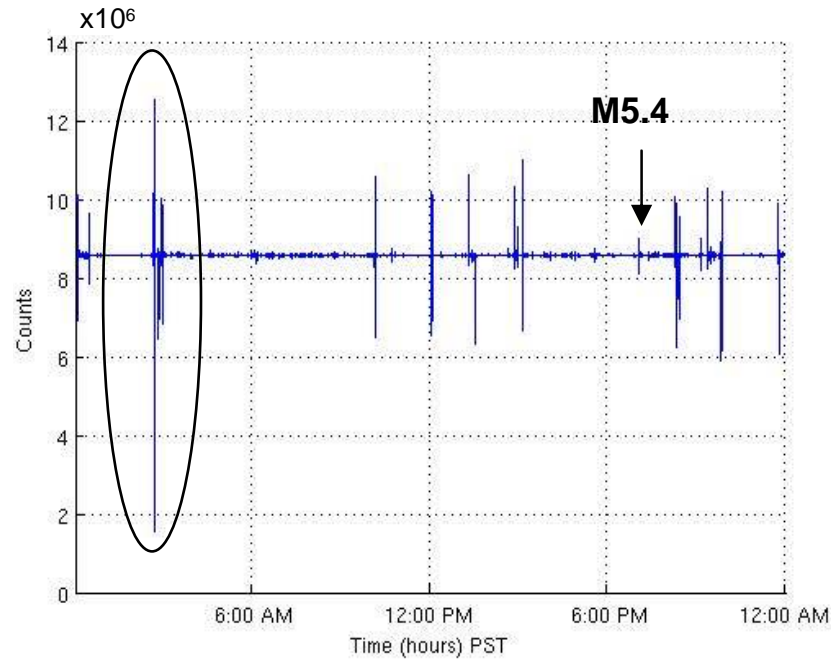

Fig. 2c. Time series E-W - day of quake (30 October).

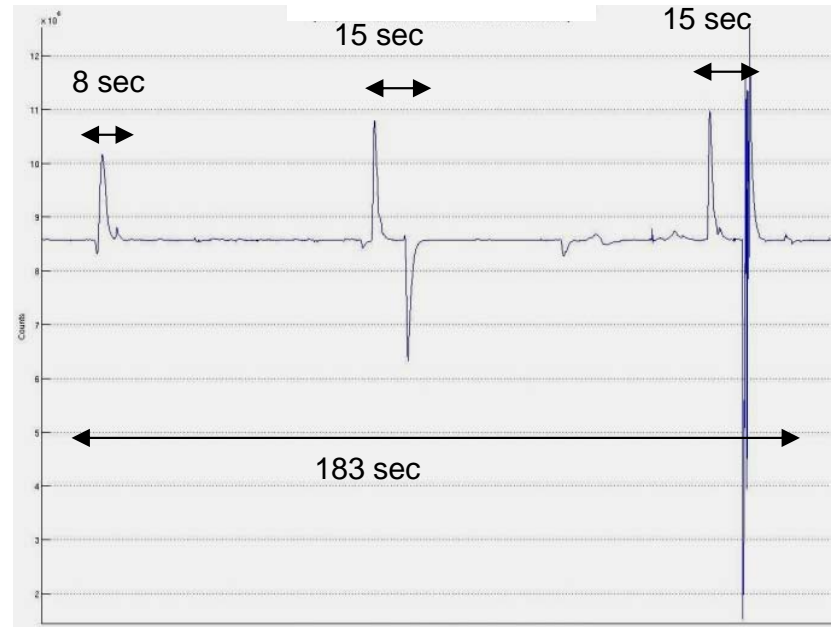

Fig. 2d. Area in ellipse (Fig. 2c) expanded.

lower limit) were first identified, then classified by "type" (positive excursions, negative excursions, and bi-polar excursions), and then counted and incremented within the "type" bins. A pulse "type" is a predominantly "positive" excursion above the positive limit, a predominantly "negative" excursion below the lower limit, or a bipolar $( \pm)$ pulsation which exceeds both limits.

In monitoring the noise environment, it should be noted that we typically never saw these long, single polarity pulsations associated with human noise at any sites. In the cases of man-made noise pulsations (e.g. a car passing), the waveform was always bipolar. The single polarity signatures suggested some type of electrical current or disturbance that started impulsively, and then relaxed slowly over several seconds without changing polarity. Lightning occasionally has this singular polarity "type", but the pulse durations are significantly shorter than $1 \mathrm{~s}$. 


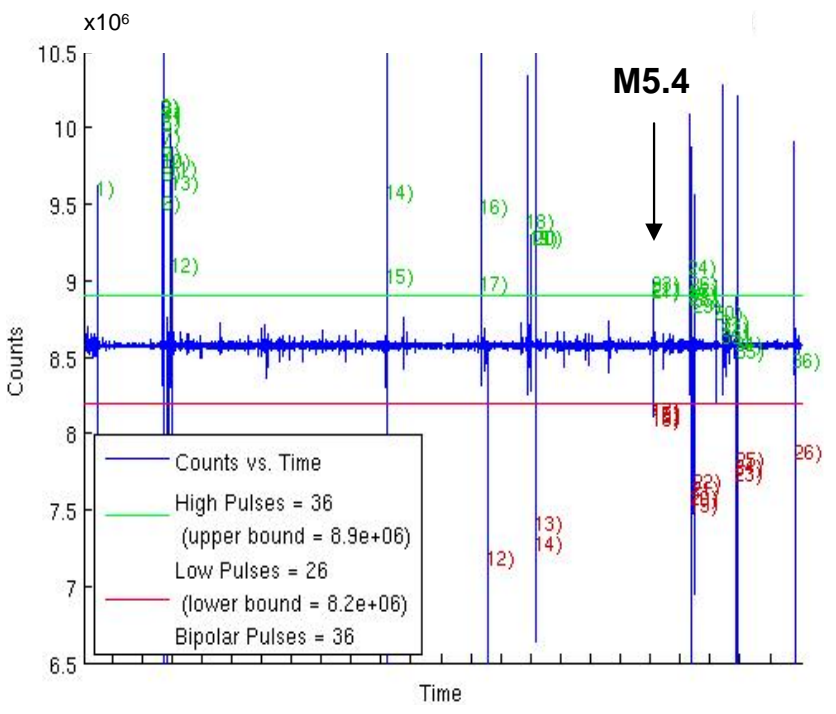

Fig. 3. Time Series E-W - Day of quake with high (green) and low (red) threshold limits (30 October). There are 36 pulses which exceeded the high threshold and 26 that exceeded the low threshold. In addition there were 36 pulses that exceeded both high and low thresholds.

Figure 4 is a plot of the number of pulses per day that exceed this $2 \times$ noise floor limit for the E. Milpitas site, and the plot was run over the entire 2 years of data in the site's history prior to the quake. After plotting all the data (a), it was apparent that there were data segments where manmade noise corrupted the data set, (e.g. tractor work near the magnetometers during July-August 2007, visits to the site by our maintenance staff (14 October 2007), and several other repeating man-made signals). We identified these contamination times, based on evidence in the area (one of our coils was actually damaged in July 2007) or interviews with the landowner noting the times of the local activities. These corrupted segments were subsequently removed from the second plot file (Fig. 4b). Both plots show elevated count totals during the summer, peaking near the end of October 2007. Note, the vertical scale has been compressed in Fig. $4 \mathrm{~b}$, but it continues to illustrate that there was a build up of pulses from the "normal" 0-10 pulse per day background levels. It was noted in Fig. $4 \mathrm{~b}$ that there were 12-13 episodes of short periods of pulsations. Most of these periods were shorter than 2-3 days. These short periods of pulses would peak at 150-250 pulses per day during 2006-2007. Analysis of a typical sequence, e.g., from 26-30 December 2006 showed 2-3 short pulse sequences per day, and the sum of sequence durations equaled $1 \mathrm{~h}$ or less. Two of these short periods were followed within a week by a small earthquake (M3-4). This may or may not be significant. However, late in October 2007 prior to the Alum Rock earthquake, the pulse rate increased and sustained these higher levels for almost 2 weeks (similar to the Loma Prieta sequence), and then decreased back to background levels in a few days after the quake. This sustained sequence over

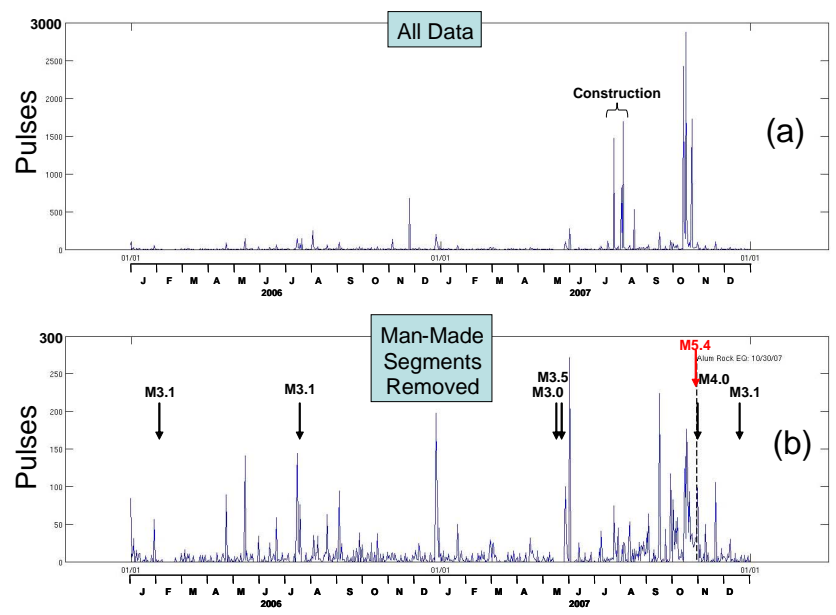

Fig. 4. Magnetic pulse count for E-W channel at E. Milpitas $(2 \mathrm{~km}$ from epicenter), unedited plot with contamination (a), and identified man-made contamination segments removed (b).

2 weeks we believe is significant in that the deformation process may be starting to avalanche.

The two M3+ quakes identified on Fig. 4b were the only quakes prior to the M5.4 that were identified within a $20 \mathrm{~km}$ radius of the epicenter (the expected range of the magnetometers).

\section{Investigation of potential magnetic noise contamination sources}

The pulsations in the data set at the E. Milpitas site could be "normal" noise from local and global geophysical sources (e.g. lightning, Pc 1, Pc 3, or Pc 4 magnetospheric pulsations), or contaminated by man-made activities, or, a combination of both. An investigation was started to identify and characterize specific signal sources at this site. Six potential sources (man-made noise and geophysical signals) were identified and investigated relative to these magnetic pulse signatures:

1. Man-made noise from electrical sources local within $100 \mathrm{~m}$ of the instrument (e.g. cars, trucks, power tools, water pumps). This also includes potential electrical impulses from nearby Lawrence Livermore Lab (National Ignition Facility-NIF testing) where large capacitor banks are discharged into one or more lasers.

2. Solar generated magnetospheric noise (e.g. Pc 1, Pc 3, Pc 4 micro-pulsations).

3. State-wide lightning.

4. Internal instrument noise (the QF-1005 instrument itself).

5. Power grid electrical currents due to electrical faults at customer locations. 


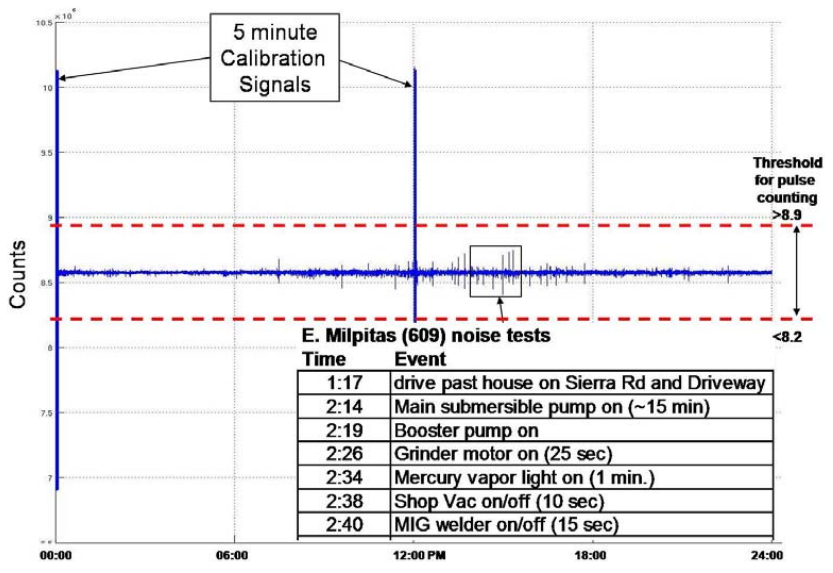

Fig. 5. Series of noise tests performed at E. Milpitas to develop a $2 \times$ noise threshold level.

\subsection{Local man-made noise}

The E. Milpitas (Site 609) is located approximately $100 \mathrm{~m}$ from two roads, and there are several equipment barns and 2 water pumping systems within $50 \mathrm{~m}$. A special set of noise tests were performed on a Sunday afternoon when the local environment was relatively quiet and could be controlled. Each large current source in the local area was identified (e.g. a deep well pump, a booster pump, welder, shop vac., etc.) and cycled on/off in a controlled test sequence, each time observing the reaction of the magnetometer instrument. In addition, cars and trucks were driven along the nearby road, and times noted. Figure 5 shows a $24 \mathrm{~h}$ time series of magnetometer data in which these vehicles and equipment sets were turned on/off at various times and recorded. The box inset at the lower right of the figure lists the actual equipment start times, and durations. The worse case noise measured at the magnetometers was less than $0.85 \mathrm{nT}$ peak to peak. That level was then doubled $(1.7 \mathrm{nT})$ and subsequent upper and lower limits ( 8.9 and $8.2 \times 10^{6}$ counts) applied to future daily data plots as a limit threshold.

It may have been possible for large current users, other than BART trains, to generate pulse type noise. One example was identified at Lawrence Livermore National Labs, $30 \mathrm{~km}$ $\mathrm{NE}$ of the site. The Lab group was contacted to determine if their National Ignition Facility (NIF) laser system was firing during the time in question. They indicated that they had fired 1 laser bank (out of 192) occasionally that day, but the times did not correspond to any of the corresponding ULF pulse times. In addition the ULF pulses at E. Milpitas were too closely spaced in time to possibly be caused by the much slower NIF firing sequences.

\subsection{Solar-generated ULF noise}

The next test compared all ten 600 series sites, which include the highest resolution, 3-axis magnetometer systems in
CalMagNet. These instruments have a frequency range from 0.01 to $12 \mathrm{~Hz}$, with a noise floor of approximately $0.1 \mathrm{pT}$ per root $\mathrm{Hz}$ at $1 \mathrm{~Hz}$. These instruments were deployed along major faults from far Northern California to the Mexican border. A time period was selected when most sites were quiet (e.g. 2-4a.m.) and the frequency band 0.01 to $0.022 \mathrm{~Hz}$ was selected which typically shows simultaneous Pc 3 and Pc 4 solar-generated micro-pulsations. Pc 3 and 4 signals are solar-generated magnetic disturbances that result in long period (e.g. 50-100 s) disturbances that can be detected world wide. Therefore, simultaneous Pc 3 and 4's can be seen across the network (See Fig. 6). However, the large pulsations detected at E. Milpitas (10-20× amplitude of Pc 3 and 4) had long durations (1-30s) and did not resemble typical Pc 3 and 4's, and most importantly, they were only detected at E. Milpitas. Therefore, these large pulsations do not appear to be solar-generated signals.

\subsection{Lightning}

Since local lightning strikes could have caused similar pulses (at least those which were less than $1 \mathrm{~s}$ wide), a lightning survey was purchased from Vaisala, Inc which included the entire state of California, for the month of October 2007. The resulting data was scanned to see if any correlations existed between the pulses observed at E. Milpitas site and any lightning events in the greater California area. Much of the lightning activity was in the northern and eastern parts of the state, namely the Sierra Nevada mountains. 29 October was the one day with the most lightning activity in the state (4420 strikes reported), and the 20 closest strikes (within $30 \mathrm{~km}$ of E. Milpitas) were identified. Figure 7a is a time series of 29 October at E. Milpitas and the lightning activity that could be time correlated is highlighted in a narrow time period (e.g. the series of lightning strikes occur only between $15: 50$ to $17: 00$ ). The remaining lightning activity occurs more than $50 \mathrm{~km}$ from this site, and appears to fall below the threshold levels used is Sect. 4.1 (e.g. a typical distant strike is shown at 05:30), and therefore were not counted. In general for October, lightning was a very minor noise (pulse) source for the data set. We used a magnitude threshold in the pulse counting algorithm (Sec. 4.1), but in the future, one could create a pulse duration threshold to further eliminate lightning contamination, and this would eliminate the need to purchase lightning data bases from outside vendors. Figure $7 \mathrm{~b}$ highlights the differences in the pulse shape and duration between lightning (bottom) and the subject pulsations (top).

Approaching the analysis from the opposite perspective, namely the pulsation activity, 17 and 24 October had the highest ULF pulse counts at E. Milpitas during October, however there were no lightning strikes on either of those days in all of California. 


\section{East Milpitas: Freq. $=0.01$ to $0.022 \mathrm{~Hz}$ East-West Magnetometer}

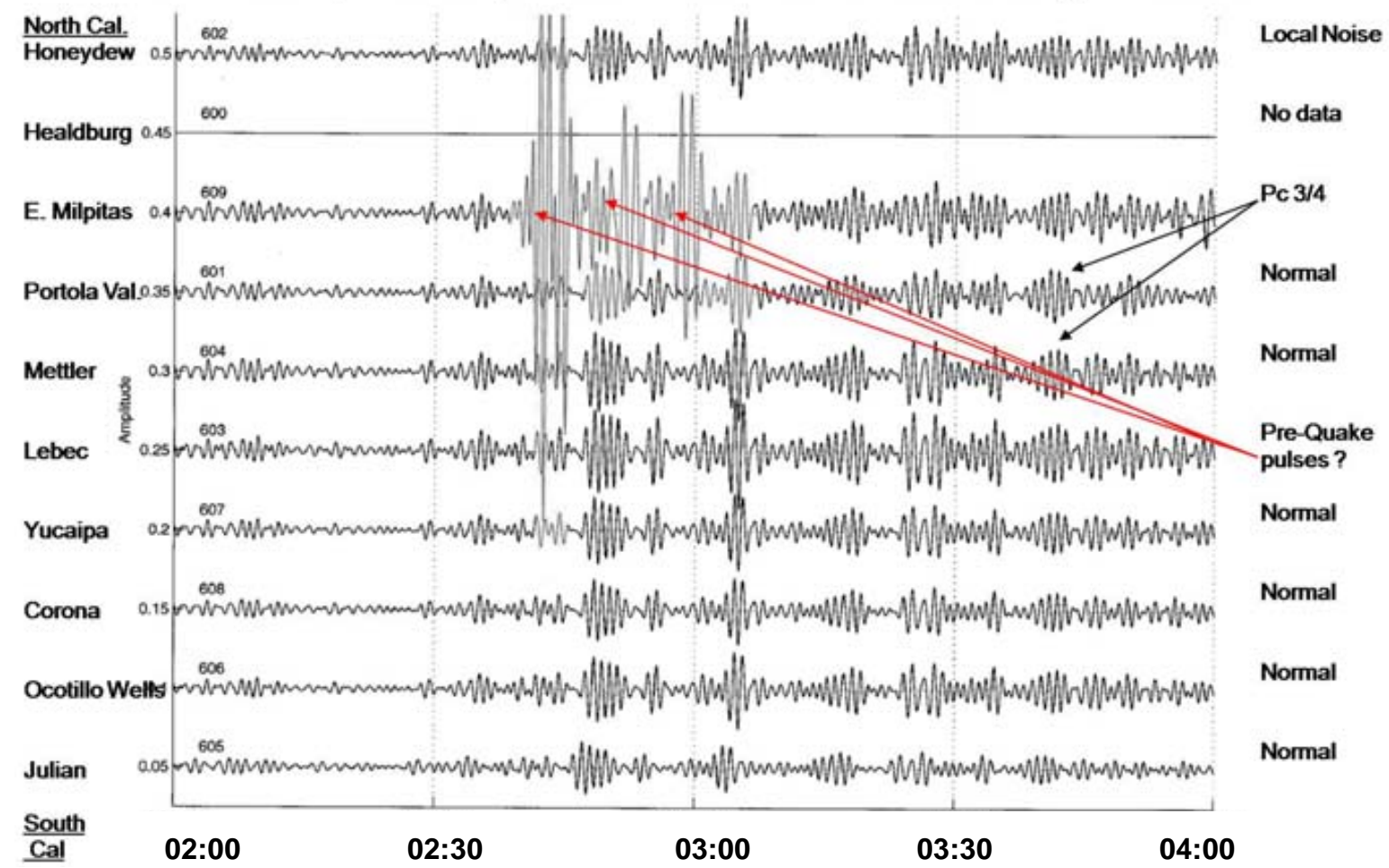

Fig. 6. Time-series comparison of Pc 3, 4 micro-pulsations from 10 California stations.

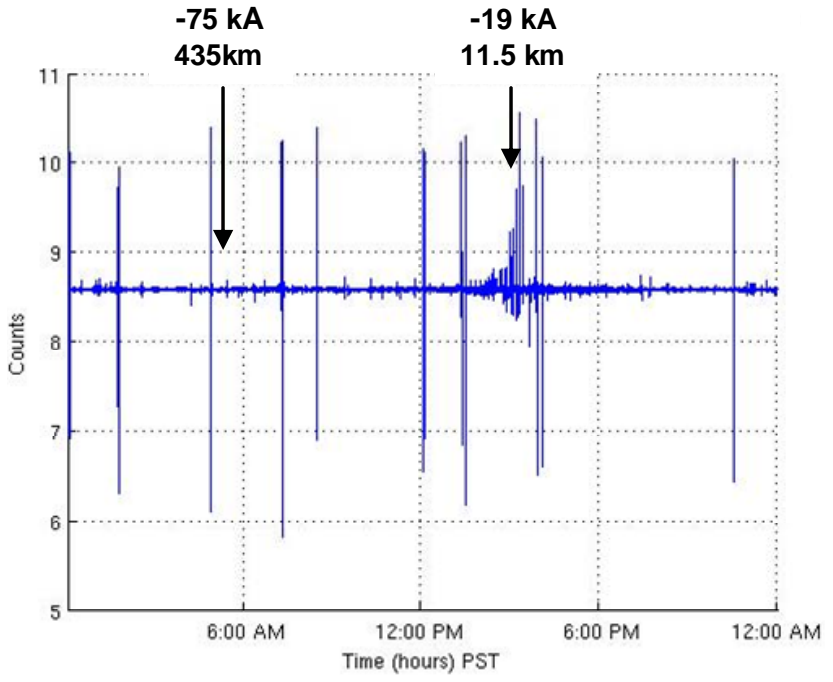

Fig. 7a. Examples of lightning detected at the E. Milpitas site on 29 October 2007 . $-75 \mathrm{kA}$ refers to a cloud to ground lightning strike, $75000 \mathrm{~A}, 435 \mathrm{~km}$ from the strike to the ULF magnetometer instrument at East Milpitas.

\subsection{Internal instrument noise}

Next, the instrument itself was tested to see if any internal electronics or software could cause the pulses. All three mag-
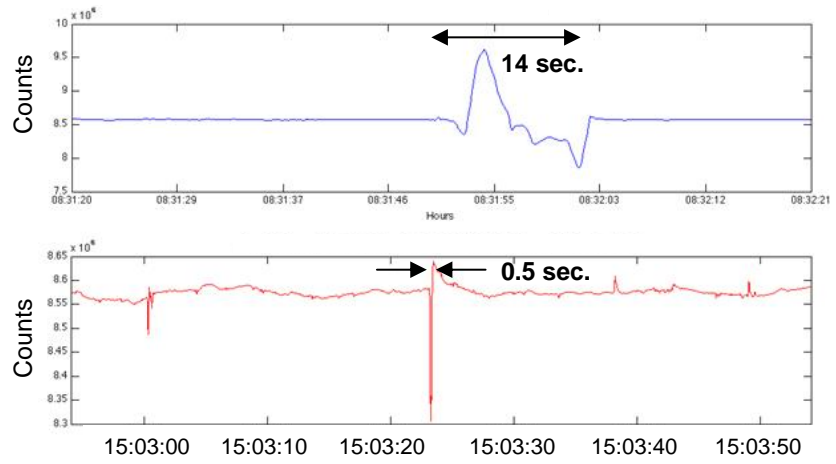

Fig. 7b. Comparison of ULF pulsation (top), possibly related to earthquakes, and lightning (bottom).

netometer channels saw the pulses at E. Milpitas, but the Air Conductivity sensor and Geophone, which share the same analog power supplies, never exhibited simultaneous pulses (hence the power supplies and analog-to-digital (A/D) converters appeared to function properly). The instrumentation power supply voltages were also recorded for a week, but no pulses were ever detected.

We looked for a case where two magnetometer instruments might have detected a local pulse to prove that a single instrument was not detecting an internally-generated noise 


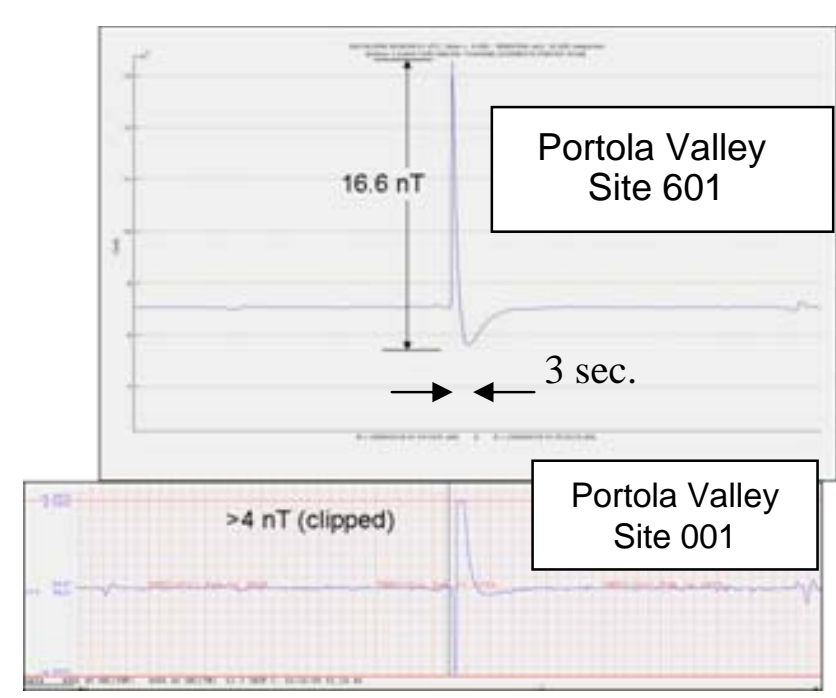

Fig. 8. The same ULF pulse, detected by 2 different magnetometer instruments, $100 \mathrm{~m}$ apart.

pulse. We found an example of a pulse detected at the prime Portola Valley site (Site 601), and since it had a second magnetometer system (an original high school-built system, Site 001) $100 \mathrm{~m}$ west of the 601 site, we compared the two data sets. Figure 8 shows that the same pulse was detected on two different magnetometers, $100 \mathrm{~m}$ apart, and therefore could not be unique to noise in one instrument. The time is synchronized via GPS, and the time scales are identical in Fig. 8. The two magnetometers utilized different electronic amplifier designs, power supplies, and different A/D units. See the CalMagNet description (Cutler, 2008) for more site details.

\subsection{Power grid fault current noise}

The area around the magnetometer site was examined for power lines and potential paths between the local equipment loads and the source power transformer where short circuit faults and current return paths could contaminate the data. This Site 609 (E. Milpitas) was not in any such fault path, nor were any of the other CalMagNet instruments.

\section{Alum Rock fault area signal characteristics}

The E. Milpitas instrument detected a number of pulsations that appeared to increase within 2 weeks prior to the Alum Rock earthquake. In this section we investigate several parameters of these pulsations in order to understand their unique characteristics relative to the quake. These characteristics include the pulse counts observed over the 2 year period prior to the quake, the pulse durations, pulse polarities, and pulse signal propagation distances. When a large solar storm occurred, the magnetometers would detect continuous
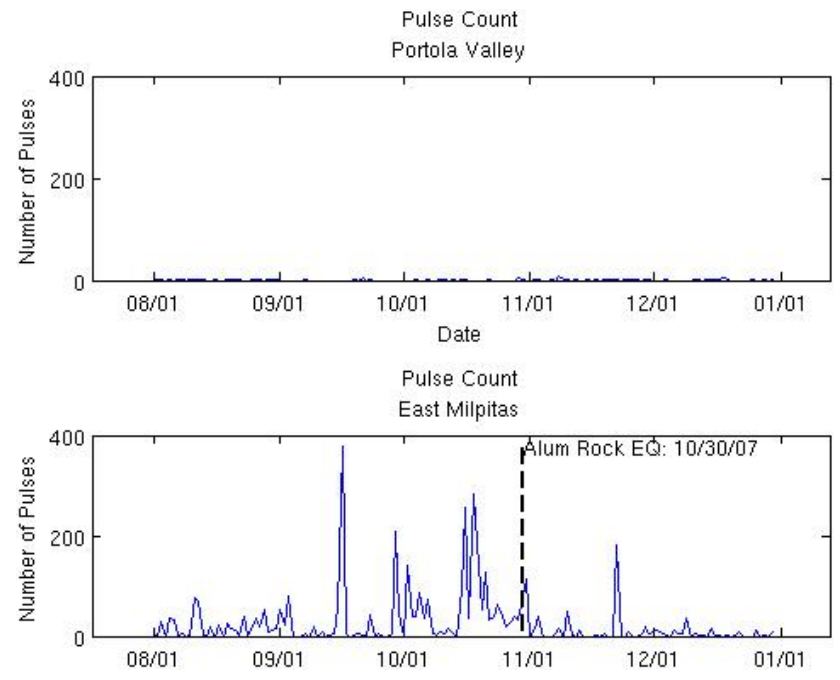

Fig. 9. Comparison of pulse counts at Portola Valley, $30 \mathrm{~km}$ west of Alum Rock (top), and East Milpitas, $2 \mathrm{~km} \mathrm{SW}$ of Alum Rock (bottom).

waveforms in the 0.01 to $5 \mathrm{~Hz}$ band. We monitor the worldwide average geomagnetic index, $\mathrm{Kp}$, and know when these continuous sequences of Pc $1, \operatorname{Pc} 3$, and Pc 4 waveforms should arrive. These solar-generated waves would last for hours or days. The pulse types observed prior to the Alum Rock earthquake were unique in that they were individual pulsations that were longer than lightning, and had other unusual characteristics, namely that a significant number of them were "unipolar", e.g. they had either a positive only or, a negative only component relative to the DC mean value of the time series data. After we looked for all discriminating features of the Alum Rock data set, we also looked for another example of a medium to large quake where there were in situ magnetometers (e.g. Parkfield M6.0 quake on 28 September 2004) to determine if similar pulsations existed in that earthquake sequence. See Sect. 6.

\subsection{Pulse counts}

We have seen the pattern of pulsation events in Fig. 4. Figure 9 here shows a comparison between the E. Milpitas site (609), $2 \mathrm{~km}$ from the epicenter on the Calaveras fault, and those observed over the same time period at the Portola Valley site (601), located approximately $300 \mathrm{~m}$ west of the San Andreas fault, and approximately $30 \mathrm{~km}$ to the west of E. Milpitas. Portola Valley has a typical background pulse rate of $0-4$ pulses per day, and rarely contains over 10 pulses per day, did not demonstrate any elevated pulse counts prior to the Alum Rock earthquake. It can also be seen that there were some episodic pulse activities at E. Milpitas throughout the year in which pulse rates rose above 150 pulses per day, but these episodes usually lasted only 1-2 days. Some of these pulse sequences were very periodic, happened during 
the workday, and through interviews with the landowner, could be attributed to local construction activities (e.g. tractors). These man-made sequences were removed from the data set. The majority of the pulse sequences were more random, and in the timeframe leading to the earthquake, the pulse rate appeared to increase above 50 to 176 per day, and remain active for more than a week, spread across both day and night. The pulse activity then returned to normal after several days post quake, and again looked normal.

\subsection{Pulse durations}

We investigated the duration of the pulsations by first identifying the pulsation above the thresholds described in Sect. 3 . Once the pulsations' amplitude was detected to be greater than twice the site background noise, they were typed and counted. The duration of the pulsations were measured and binned from 1 to $30 \mathrm{~s}$. Figure 10 shows the distribution of pulse durations over the 2 year period 2006 through 2007, and showed that there were many pulses in the range of 1$30 \mathrm{~s}$. These durations were much longer than any humangenerated noise source that we had observed during the noise characterization tests described in Sect. 4. Geophysical Pulsation-continuous activities such as Pc 3 and 4 signals did exist regularly in the data, but these signals were below the threshold used in Fig. 6, and were considerably smaller ( 0.1 to $3 \mathrm{nT}$ ) than the amplitude of the pre-earthquake pulsations in question (e.g. 3-20 nT).

\subsection{Pulse polarities}

Not only were the pulse durations unusual (1-30 s), but they also had unusual singular polarities (+ or - only) as well as bi-polar waveforms $( \pm)$. The same data set for 2006 through 2007 was reviewed and a query was set to count the positive only, negative only, positive (starting) bi-polar, and negative (starting) bi-polar pulses. Table 1 below compares the 2 year totals of the polarity counts with the 2 week period just prior to the quake (15 to 31 October 2007). The percentages to the right of the table show that the 2 week pre-quake period is responsible for $36-45 \%$ of all the pulses (identified by polarity) over the 2 year period, even though this 2 week period only represents approximately $2 \%$ of the total time in the prequake 2 year data set. It is also interesting to note that the 2 week pre-quake period showed 7227 single polarity pulses (sum of the + and - pulses) as compared to 4396 total bipolar pulses. All human-generated noise that was identified in the study was always bi-polar.

\subsection{Propagation distance}

Special field tests were performed using an identical portable magnetometer (unit 699) to the unit at E. Milpitas, and data was collected at 4 remote, temporary locations (labeled Temp1-Temp4) as shown on the map in Fig. 11. These data collections were performed on the day after the earthquake
Distribution of Pulse Durations

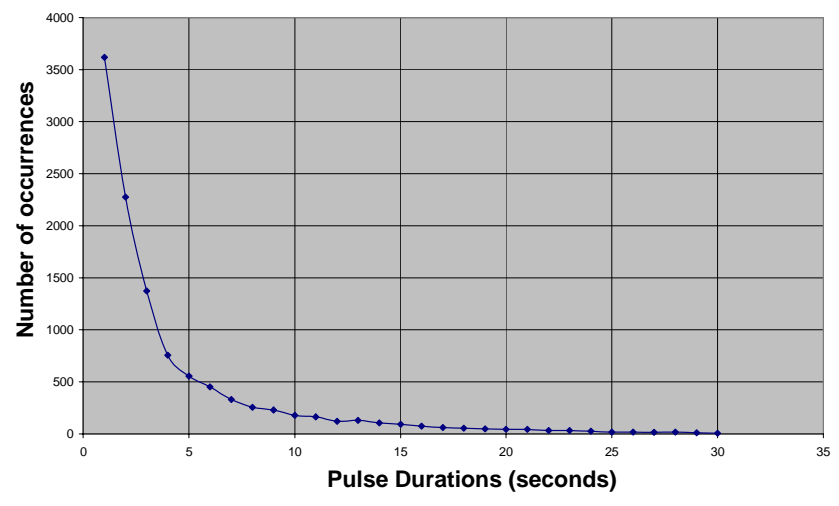

Fig. 10. Distribution of pulse durations that violated the $2 \times$ background noise threshold at E. Milpitas Site for all of 2006 and 2007.

Table 1. Counts of individual Pulse types at Alum Rock (E. Milpitas).

\begin{tabular}{llll}
\hline Pulses & $2006-2007$ & 5 to 31 Oct 2007 & $\%$ of Total \\
\hline UP & 11282 & 4108 & 36 \\
DOWN & 9176 & 3119 & 34 \\
BIPOLAR_UP & 5993 & 2689 & 45 \\
BIPOLAR_DOWN & 4757 & 1707 & 36 \\
\hline
\end{tabular}

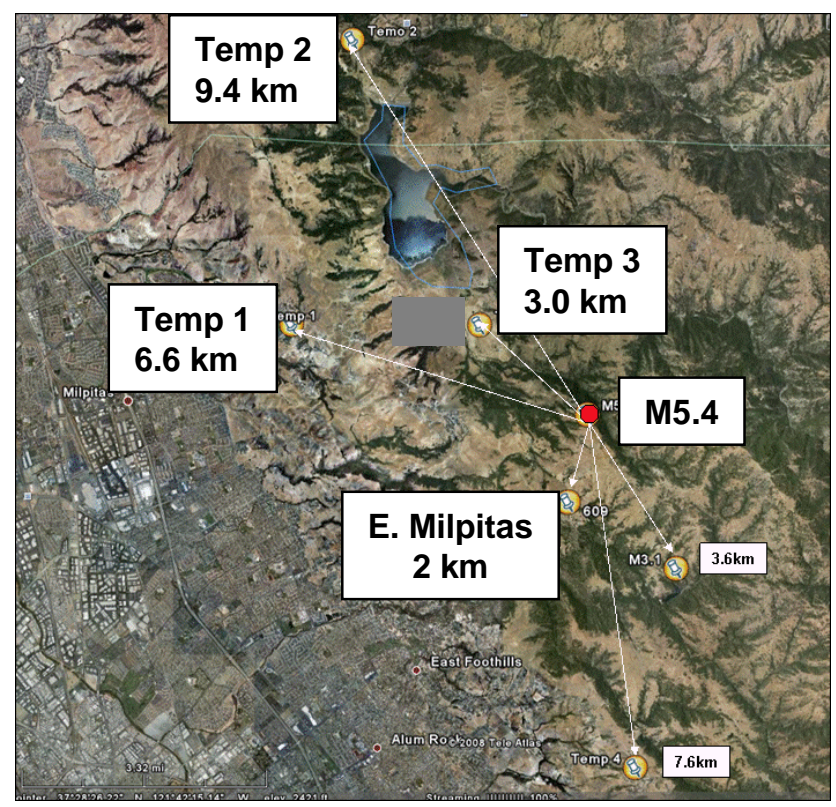

Fig. 11. Map showing relative locations of the M5.4 quake, Site 609 (E. Milpitas), and Temporary data collection sites: Temp 1-4. 


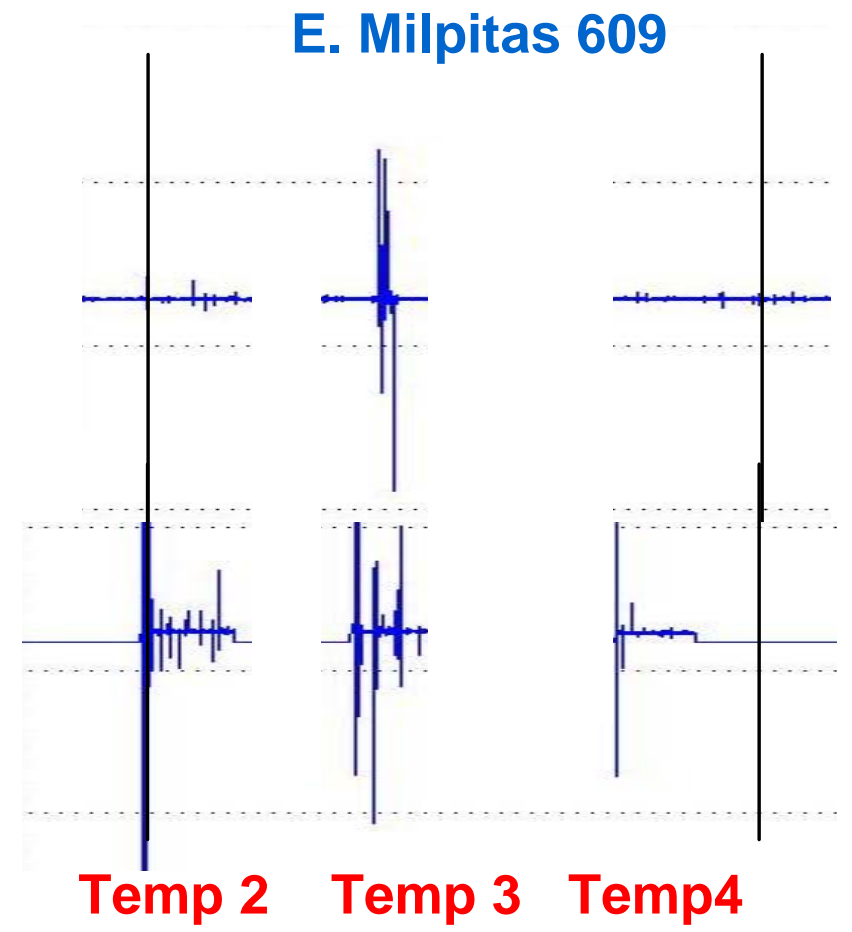

Fig. 12. Corresponding Time series data for fixed Site 609 (top) and Temporary Sites 2, 3, and 4 (bottom).

(31 October local) to determine how far the pulses could be detected from the epicenter. Figure 12 shows the overall signal comparison of TEMP sites 2, 3 and 4. Temp 1 was omitted from this figure, because it was $6.6 \mathrm{~km}$ away, located perpendicular to the fault trace, and did not show any correlation. Since we were only able to record for $30 \mathrm{~min}$ at each temporary site, many of the large pulses detected at the continuously recording Site 609 occurred when the portable unit (699) was being moved and was not recording. Figure 13 shows the signals from TEMP3 (699) and the fixed site (609), expanded to show more detail. Only three significant pulses were correlated at Temp 3 site, $4.3 \mathrm{~km}$ to the northwest of the fixed E. Milpitas site, $3.0 \mathrm{~km}$ from the epicenter, along the Calaveras fault trace. The amplitude and time scales are identical between Site 609 (E. Milpitas) and unit 699 (Temp site equipment). Both sites include identical instruments, both used GPS timing, and both sites showed strong correlation for small magnetospheric pulsations ( $\mathrm{Pc} 1$, 3, 4's). In Fig. 13, one can see a pattern of 3 spikes (but opposite in polarity) at the temporary site, and offset at the fixed site. Pulses A and B are similar to A' and B' (but opposite in polarity). The pattern continues with pulses $C$ and $C^{\prime}$. These Temp 3 pulse patterns are consistently offset by $8 \mathrm{~s}$ (earlier) from the fixed site. There is additional analysis of this offset in the Discussion Section.

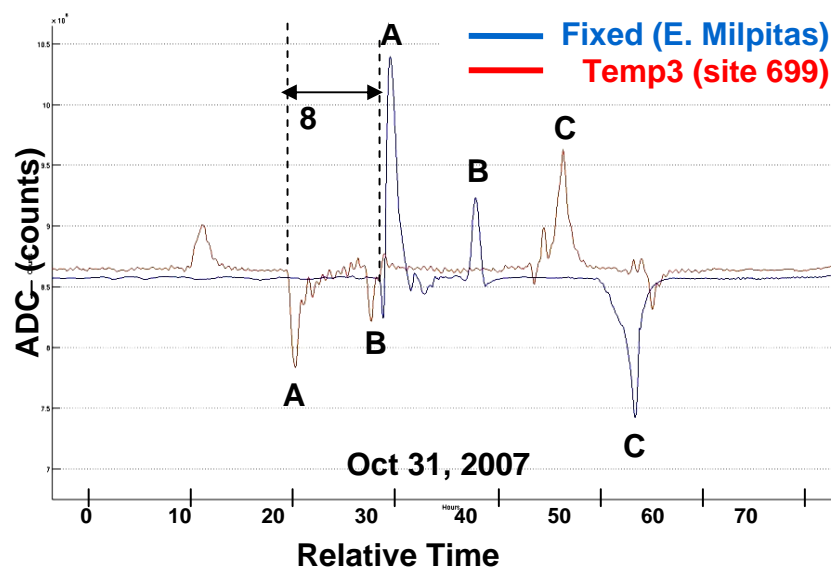

Fig. 13. Pulse comparison timeline showing 8-s offset between East Milpitas (Site 609) and Temp 3 (Site 699).

\section{ULF comparison with another California Earthquake: Parkfield M6.0 28 September 2004}

The only other significant earthquake example in which we had access to ULF data was Parkfield (M6.0 on 28 September 2004). We re-examined that event and discovered similar pulses in the raw data files. Figure 14a illustrates the pulse structure on 13 September, the start of the active pulsation period at Parkfield, 15 days prior to the M6 quake. Expansion of several pulse patterns identified by the ellipses in Fig. 14a show similar, large and elongated pulses over various time segments in Fig. 14b and c. The local area was quiet. Solar activity was nominal (Kp was 3 , and Electron flux was $10^{3}$ ) and there were no local quakes $>\mathrm{M} 2.5$ during this time period. The instrument is located on a farm, and since the activity continued for several days, and more importantly, at night, it did not seem likely that human activity was the cause for these pulsations. Figure $14 \mathrm{~d}$ and e show the pulse activity for Parkfield over a one year period, 2004. The Vertical channel (PK3) was selected because it was relatively quiet. Figure $14 \mathrm{e}$ illustrates a relatively small pulse count increase prior to the quake at 14 days and 1 day prior to the earthquake. Analysis of the time series data for these smaller pulses in Fig. 14a showed occurrences of unipolar pulses, similar to those observed at Alum Rock. The post earthquake period also shows several periods of high pulse counts in Fig. 14e during which there were no aftershocks (similar to Alum Rock and Loma Prieta earthquakes). One might expect that the post quake period to include major stress redistributions, and perhaps, corresponding current generations. One major difference is that the pulses at PKD (Parkfield) were smaller than those seen near Alum Rock. This could be due to the quake epicenter being $19 \mathrm{~km}$ from the PKD magnetometer instrument (vice $2 \mathrm{~km}$ for Alum Rock). Although the Parkfield quake was larger (M6 vs. M5.4), the geology 


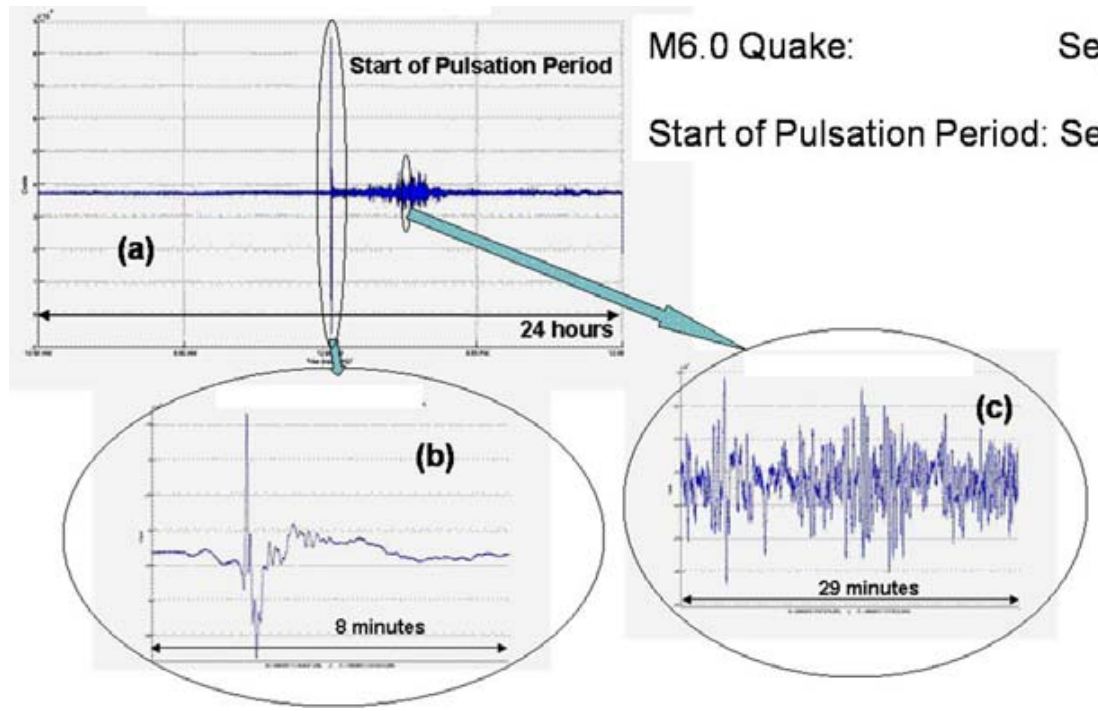

Fig. 14. (a) $24 \mathrm{~h}$ time series plot at Parkfield (PKD, and (b) and (c) time expansions showing pulsation activity at Parkfield station 15 days prior to the M6.0 earthquake.
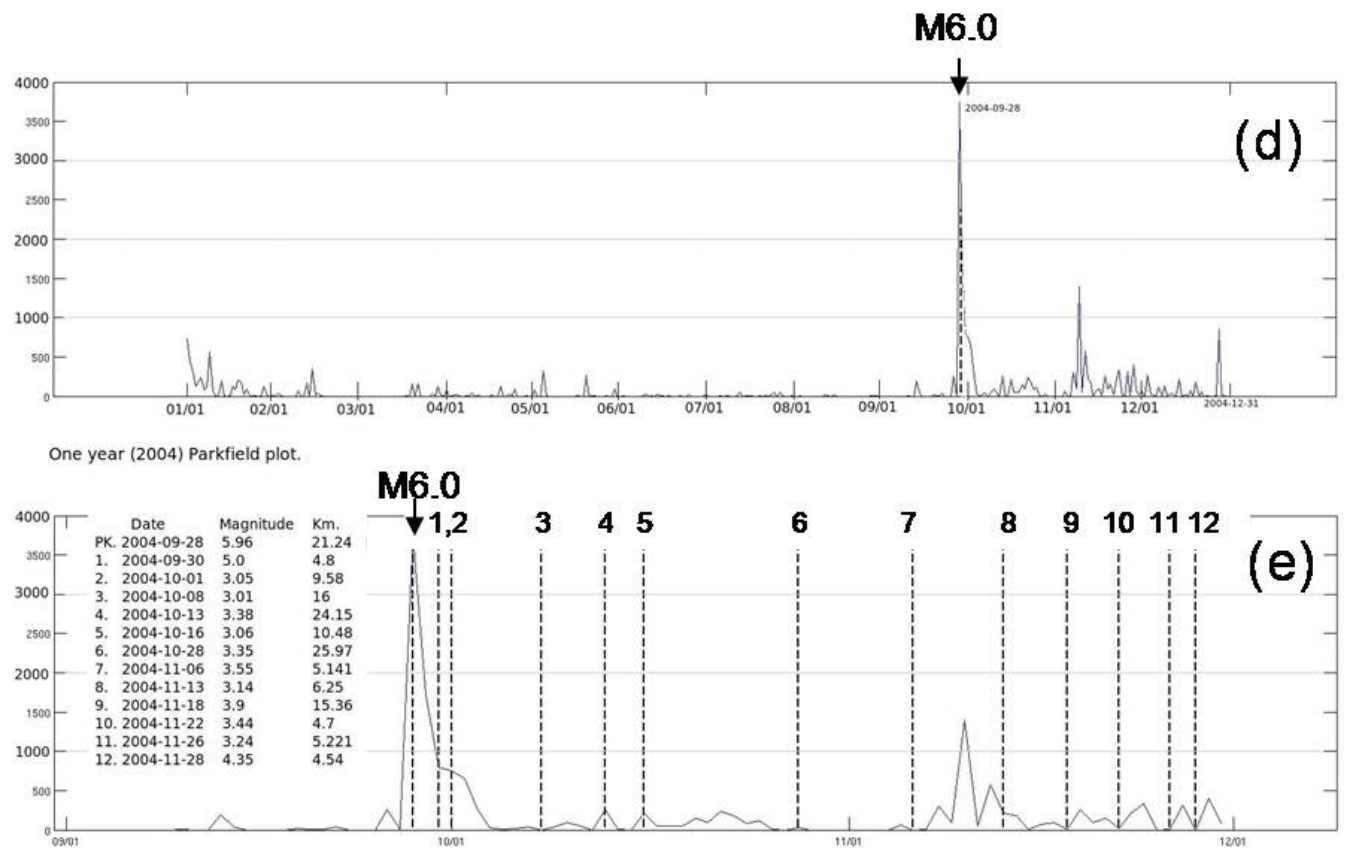

Fig. 14. (d) Pulse count for Parkfield (all 2004), and (e) expansion for September-December 2004 showing earthquakes (dotted lines) and table of corresponding magnitudes and distances from PKD site. Note: 13 more aftershocks occurred on 28 September 2004 with magnitudes from 3.06 to 4.71 .

of the area northeast of the fault line has been determined to be highly conductive during an MT survey taken in the area (Unsworth, 2000), and this may have resulted in additional attenuation of the signal since the conductive layers exist between the epicenter and the PKD instrument.

The PKD site did not detect any significant $0.01 \mathrm{~Hz}$ signal similar to the Loma Prieta quake, but it did detect very large Pc 1 micropulsations ( 0.2 to $0.9 \mathrm{~Hz}$ energy band) from $2 \mathrm{a} . \mathrm{m}$. until the quake at 9:15 a.m. local. These Pc 1 micropulsations were subsequently analyzed (Bortnik, 2007, 2008a, b), and even though they may not be generated by the quake itself, their propagation through the ionosphere to the ground appeared to be enhanced during quake episodes. Bortnik demonstrated that Pc 1 occurrences were statistically significant to earthquake occurrences near Parkfield, only when the Pc 1's appeared in the daytime within several days prior to 

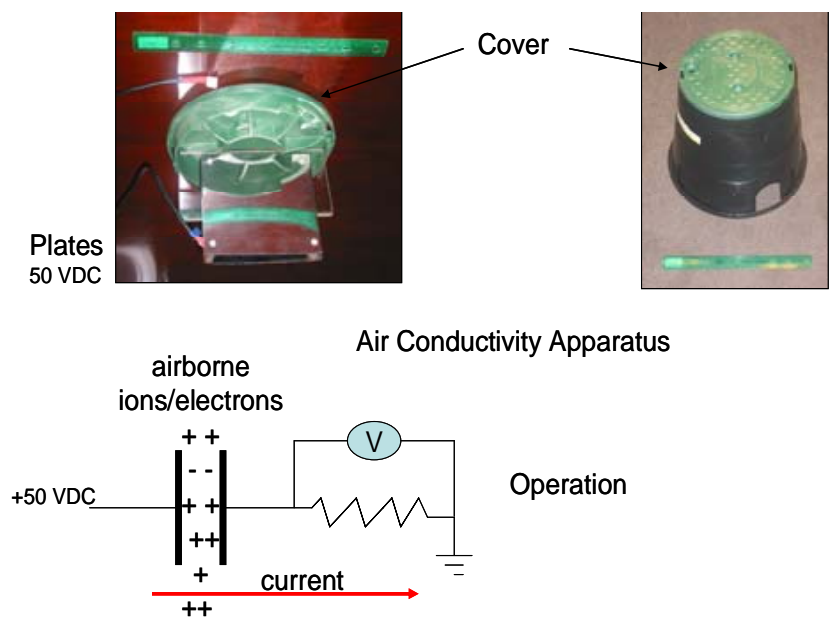

Fig. 15. Air Conductivity sensor description.

the quake. The alteration of the ionosphere above the epicenter region has been reported in a number of papers (Liu, 2001, 2004).

There were no air conductivity instruments near Parkfield prior to this earthquake.

\section{Air conductivity observations at Alum Rock (Calaveras Fault)}

An air conductivity (AC) sensor was placed at the East Milpitas site (609) for a year prior to the quake. The sensor (Fig. 15) consists of a simple pair of stainless plates, with one plate charged to $50 \mathrm{VDC}$, and the other plate connected through a resistor to ground. The systems were tested and shown to be responsive to both positive ions and negative (electrons) charge carriers. The air conductivity (AC) sensor at E. Milpitas was upgraded in May 2007 to cover the plates (using a closed-top fiberglass cylinder with an open bottom) so that rain would cause less contamination in the sensor.

Several days prior to the quake, there was no appreciable rain (a contamination source) and yet the sensor saturated for almost $13 \mathrm{~h}$. Figure 16 illustrates the single day rise in conductivity levels (saturated for $13 \mathrm{~h}$ ), while there was no rain that day and the relative humidity remained in the 70 percent range.

The primary difficulty with these units in the field is fog and rain which condenses moisture on the plastic plate separators and contaminates the data whenever the relative humidity (RH) exceeds 95\%. Figure 17 illustrates the field verification of this effect.

Figure 18 is an expanded version of air conductivity data for the month of October 2007. It shows saturated periods due to rain (100\% RH) on 9 and 12 October. However, the unit saturated prior to the quake for $13 \mathrm{~h}$ when RH was well below the saturation level $(74 \%)$ as determined by checking 2 local weather stations in the hills near the site. Something else was causing the saturation.
The polarity of the signals from the AC instrument at E. Milpitas indicated that the ionization was predominantly positive ions, but further investigation showed that the sensor detected 4 periods of negative charge carriers (See negative areas identified in red within Fig. 18). This is significant because we had not detected negative signatures in the data prior to this time.

\subsection{Other potential sources of air conductivity changes}

The Air Conductivity instruments in the field are not mass spectrometers, and therefore they cannot discriminate between p-hole carriers (oxygen anions) and radon (or radon's secondary products). However, the data clearly showed that which ever mechanism causes this ionization phenomenon, it must be able to account for the high rates of ionization, as well as both the positive and negative charge products in the air above the quake area.

It has been reported that these ionizing particles also affect relative humidity, e.g. ions capture water molecules and reduce relative humidity. The present and future CalMagNet instruments are also being retrofitted now with relative humidity sensors mounted adjacent to the air conductivity assemblies to provide more accurate relative humidity information at each site.

\section{IR data (GOES-West satellite)}

The GOES satellite IR Imager data, specifically the long wave infra red-IR: (10.7-12 $\mu \mathrm{m})$, was obtained to analyze the infra red environment around the greater San Jose (Alum Rock) area. This geosynchronous satellite instrument has a $4 \mathrm{~km}$ pixel dimension, and a specific pixel was identified just north of the epicenter, and subsequently analyzed for a night time cooling slope phenomenon. Every night after the sun sets on a portion of the earth, the corresponding area is expected to cool over $12 \mathrm{~h}$, with a resulting negative slope in temperature profile for each pixel of the frame. The larger area image (hundreds of pixels) around the Bay Area was also analyzed to determine the overall trends for these temperature cooling curves. In recent research by NASA/JPL (N. Bryant, personal communication, 2007), areas surrounding an impending large earthquake suddenly manifest an "apparent heating" effect where the temperature appears to rise in the middle of the night. This rise in IR energy is not a function of black body radiation, but rather is a semiconductor effect whereby airborne ions are neutralized, and the energy given up is seen as an Infra Red (IR) energy burst. Figure 19 show a schematic of the concept of using the night time cooling curves to check for anomalous "apparent heating" during the night time. The 3 year history of the Alum Rock area data was reviewed and the night time cooling curve of the pixel, with a negative slope of -0.991 degrees per hour, was calculated and is shown with the (almost) horizontal red line as 


\section{E. Milpitas (Alum Rock) 2007}

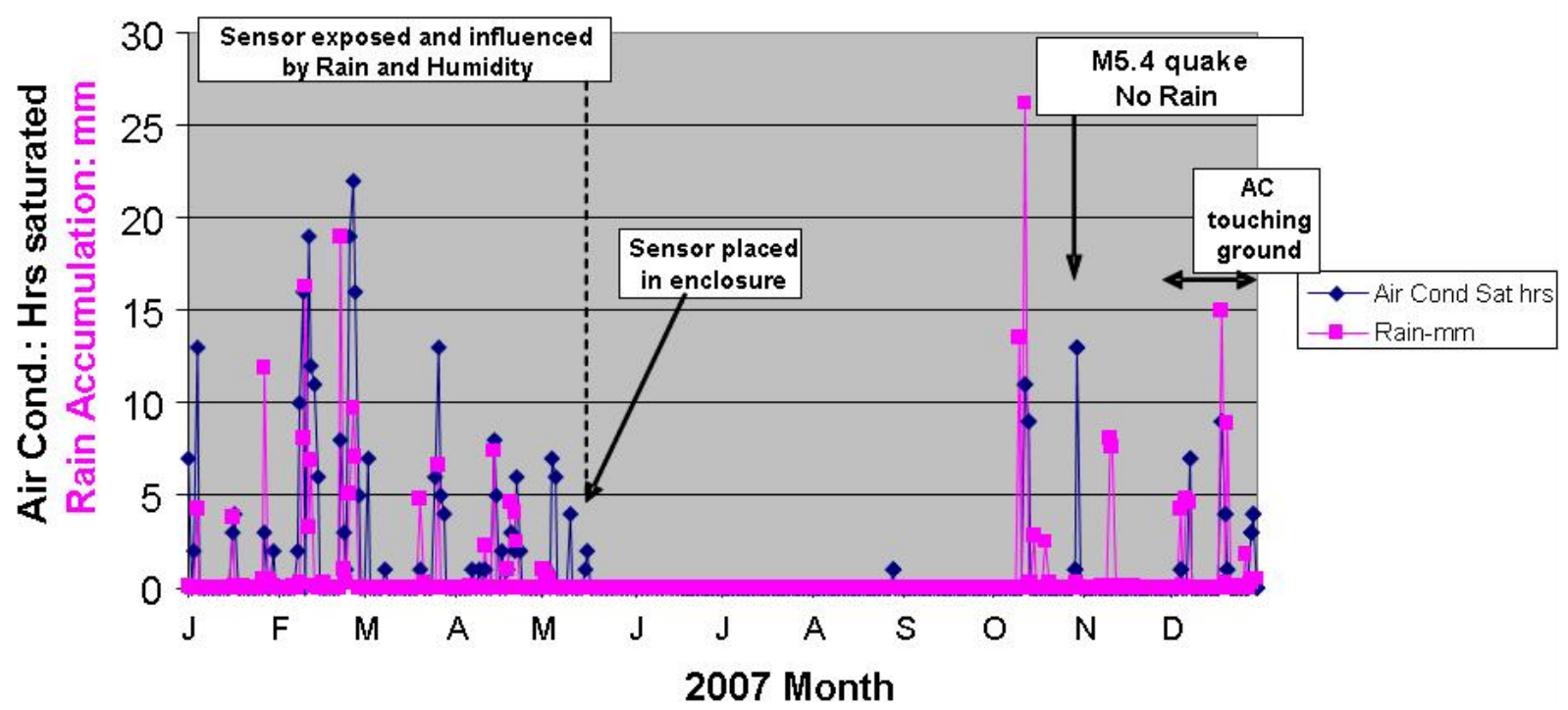

Fig. 16. Complete 2007 Air Conductivity and rain data for E. Milpitas (Site 609). Rainfall (red) contaminates the data (blue) and causes the sensor to saturate for hours at a time.

shown in graph in the right side of Fig. 19. The slope of the night time period for 17 October 2007 (13 days prior to the quake) however, is +0.3616 (blue line).

This "apparent heating" is not seen in the local ground temperature, but as an energy or "apparent heating" similar to the IR signal seen in lab experiments by Freund (2007a, b, c) using a Bomem IR spectrometer with the stressed granite sample. In this lab experiment, it was confirmed that the process of neutralizing the charge carriers ( $\mathrm{P}$ holes) in the surrounding air resulted in an IR signature, with maximum energy in the 8 and $12 \mu$ m wavelength bands. See Sect. 8 of this paper.

The same slope study performed for all the pixels over the larger northern California scene, as illustrated in Fig. 20.

The white areas in the color enhanced images depict normal 3 year history of night time cooling (negative temperature slope), grey is cloud cover (too few points to calculate a slope), yellow and pink are increasingly positive slopes $(>+0.2$ and $>+0.3$, respectively), and red is more intense positive slope. Note: many of the "red" areas are suspect since they lie adjacent to grey (cloud) areas where there are too few data points to obtain accurate slopes. These red/grey transition areas were ignored. The Calaveras fault line is shown as a black line to the lower right of the San Francisco Bay in these images, and the quake event is shown as a red dot, only on the 30 October image. These images are for the evening and early morning of each day marked on the images (e.g. 10 p.m. of the prior day to 6 a.m. for the numbered day shown on the image).
It can be seen that the apparent heating (yellow and pink areas) were generated after comparison with slopes from the previous 3 year average, and these yellow areas are spread over a wider area than just the epicenter region. It is estimated that there is "noise" in these images which may be caused by compression heating of the westerly winds as they impact the coast, Easy Bay, and Sierra Nevada mountain ranges, before passing over the mountains. The yellow areas are very evident well away from the epicenter region, and since they are barely positive and so common, they were ignored. The stronger positive slope (pink area) near the area around the fault zone (e.g. 17 October) is consistent with other IR studies near larger earthquakes (Ouzounov, 2007), and may suggest that the increased stress pattern is spread over a significant area (tens of kilometers), well beyond just the local epicenter region. The signal-to-noise of this heating appears to be marginal, and this medium sized M5.4 quake may also be marginal for this heating effect. Larger earthquakes have shown higher signal-to-noise levels (Ouzounov, 2007).

\section{Discussion}

Having now looked at each EM data set, and the corresponding noise sources in each set, we compared the 3 sets together to see if there was a consistent pre-earthquake set of signals. Figure 21 shows each data set, normalized to their highest reading in October 2007, and plotted together to allow a comparison of the trends. It can be seen that there is a consistent increase in signal approximately 2 weeks prior to the quake 

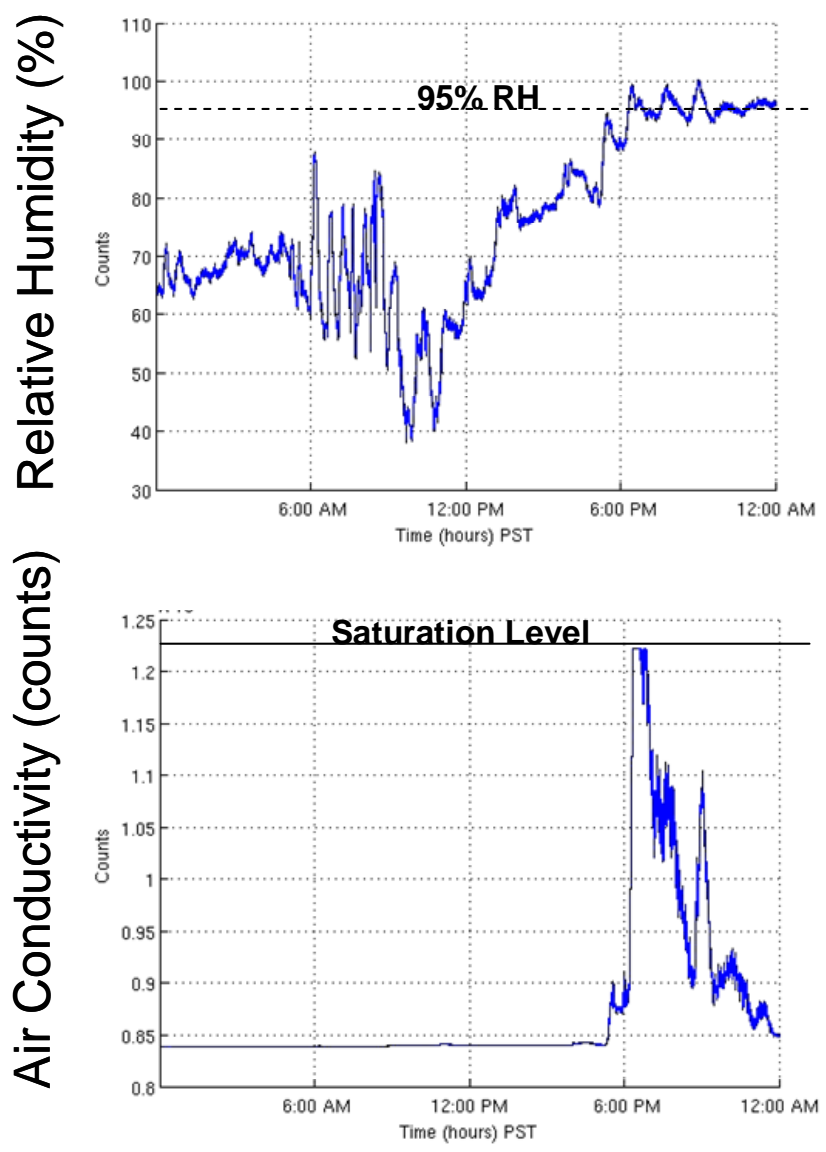

Fig. 17. Relative humidity $(\mathrm{RH})$ contamination of the Air Conductivity sensor. When RH exceeds 95\% (top panel), the plate separators become moist, start conducting, and the sensor output saturates (bottom panel).

when pulse counts reach a maximum, IR slope reaches its highest positive value for the pixel close to the epicenter, and air conductivity also starts a pattern of positive pulses before saturating during the evening prior to the quake.

Again, it should be noted that this quake is only a medium intensity quake, and the signal-to-noise ratio was not expected to be overwhelming. We plan to repeat this analysis for larger quakes, and determine if the signal-to-noise ratio (height of the signatures above background noise) is larger and more dramatic.

\subsection{Lab data comparison}

\subsubsection{Magnetic fields}

This field data can be compared, (at least qualitatively) with laboratory data collected during rock stressing experiments. Freund experiments with currents (Freund, 2006, 2007a, b, c) showed a strong correlation of currents passing through the rock samples when new stress was applied to the sample. These currents (pulses) would be expected to produce corresponding magnetic pulsations. When extrapolated from the small rock sample to the size of an earthquake rupture zone, these currents would be expected to grow accordingly. There is concern in the community whether the currents deep in the earth might be "neutralized" where there is ionic water which could "short circuit" the current paths. Subsequent lab tests have demonstrated that these currents can at least pass through ionic water boundaries and continue through adjacent rock layers. However, the lab tests are not necessarily representative of the conditions (pressure and temperature and rock interfaces) that exist deep in the hypocenter regions.

\subsubsection{Pulse propagation}

In order to understand this offset, we reviewed the lab experiments (Freund, 2006, 2007a, b, c) where the generated current impulse velocity was measured. That experiment showed that a rock sample being hit with a steel ball at supersonic speed will generate a current impulse that propagated along and through the rock sample. The current was first measured from the impact point at one end of the rock sample, and then detected at the other end of the sample. The propagation speed of this current pulse was measured at 200-250 m per s.

In the field test, the epicenter was $3.0 \mathrm{~km}$ from Temp3, and $2 \mathrm{~km}$ from the fixed Site 609 in Fig. 11. If the underground current source (similar to the p-hole carrier current demonstrated in the lab) had a propagation path component parallel to the E-W coils at the 2 observation points, and if this current burst originated between the two observing sites (near the epicenter area), then one would use the right hand rule (a current in a conductor induces a magnetic field around the conductor), and the polarity should be opposite at the two observing sites (up at one site and down at the other).

The $8 \mathrm{~s}$ offset between the arrival of the pulses at the fixed site (609) and the Temporary site (699) is also interesting. The distances to the epicenter from the fixed site and Temporary site in this field experiment $(2 \mathrm{~km}$ and $3.0 \mathrm{~km}$ respectively) divided by $200 \mathrm{~m} / \mathrm{s}$ propagation rate, results in propagation times of $10 \mathrm{~s}$ and $15 \mathrm{~s}$ respectively. If it took $10 \mathrm{~s}$ for the charge carriers to reach the vicinity of the TEMP3 observation point, and $15 \mathrm{~s}$ to reach the vicinity of the fixed site, the difference of the time of arrival ( $5 \mathrm{~s}$ calculated, versus $8 \mathrm{~s}$ observed) is certainly within a order of magnitude of what might be expected, based on what was observed in the lab. We also do not know that these pulses originated exactly at the epicenter, and they may have been farther from the epicenter, causing longer propagation times and increasing the $5 \mathrm{~s}$ delta. The difference in arrival time also seems to imply that the current/magnetic pulses are propagating at this slower rate to the magnetometer sites, where they are detected only when they are in the immediate vicinity. This could account for some of the larger amplitude signals when the $1 / \mathrm{R}^{3}$ signal attenuation is factored into the propagation equations. The large signals could be caused by either 


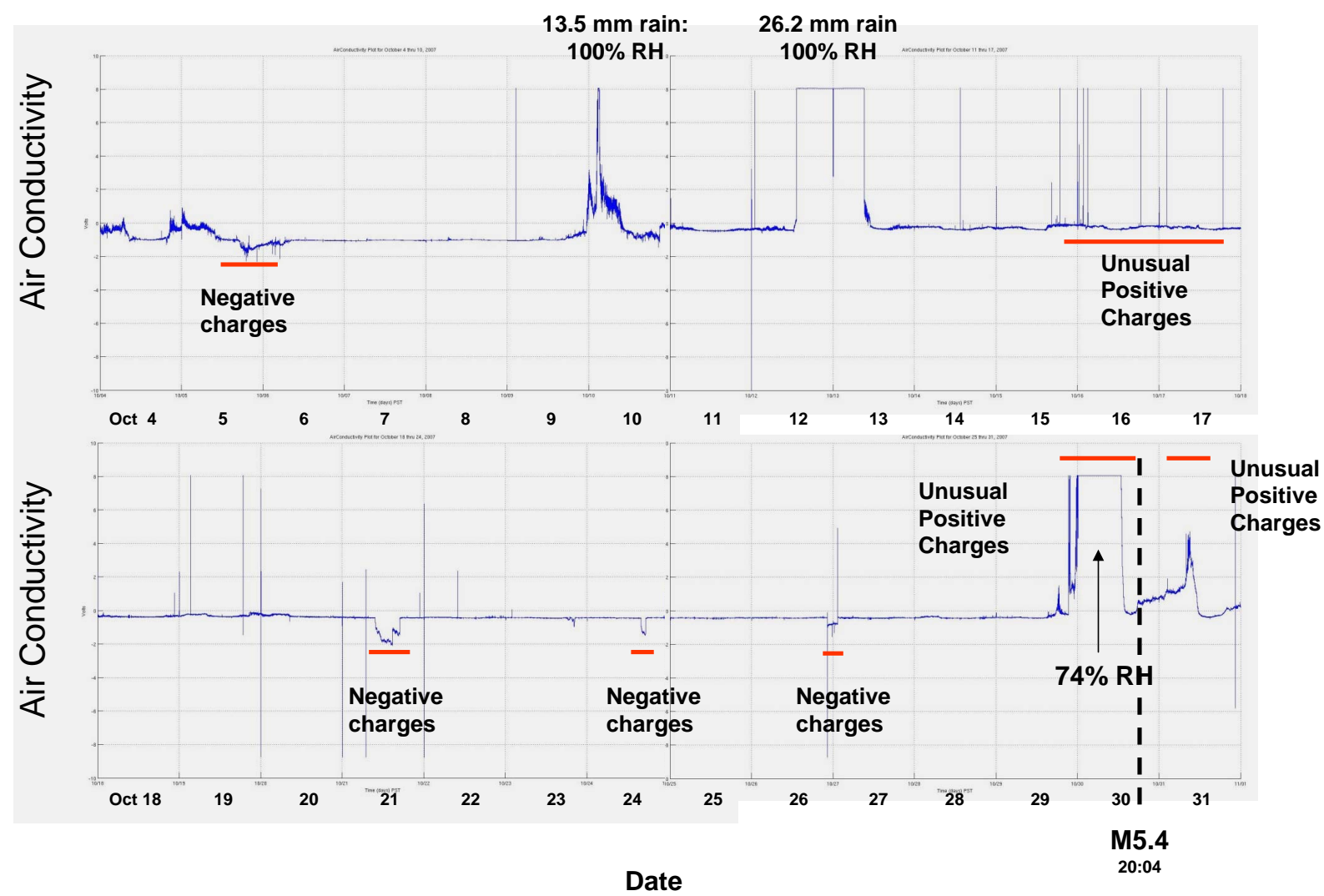

Fig. 18. Air Conductivity (expanded for October 2007) at E. Milpitas site. Unusual periods of positive and negative excursions are underlined in red $(5,15-17,21,24,26,30$, and 31 October $)$.
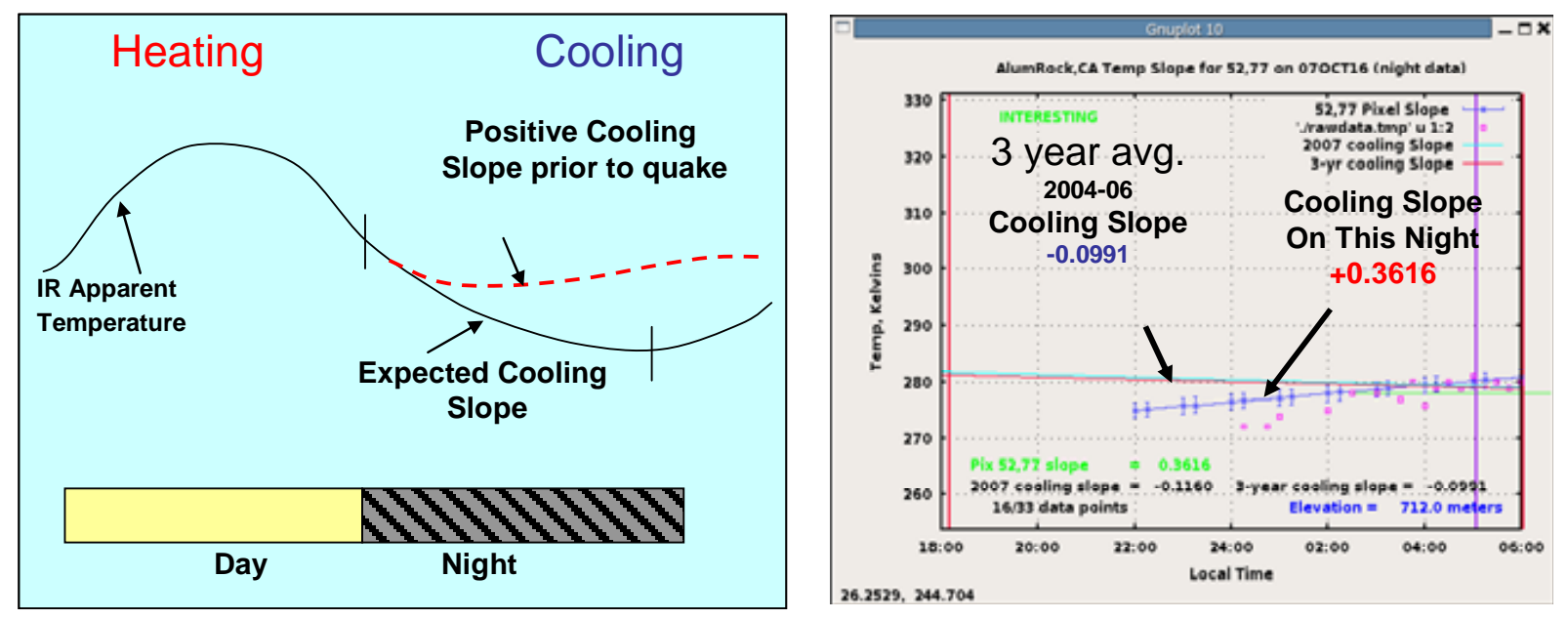

For Each Pixel

\section{(10.7um) - (12 um) \\ (long wave infrared window) \\ $4 \mathrm{~km}$ pixel size}

Fig. 19. Typical IR cooling at night time (left), with cooling slope at Alum Rock (right). 


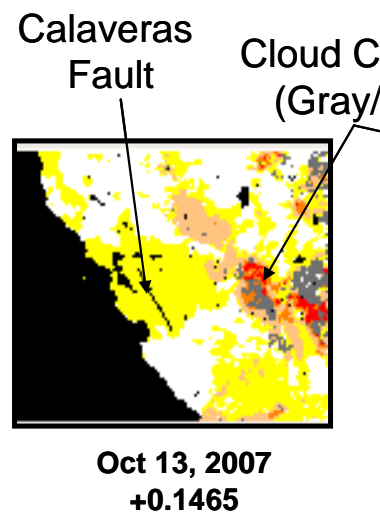

Covered

3 yr avg. slope: -0.0991

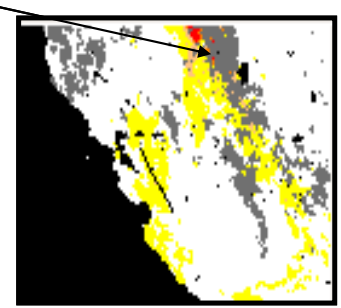

Oct 16, 2007

Cloud Covered

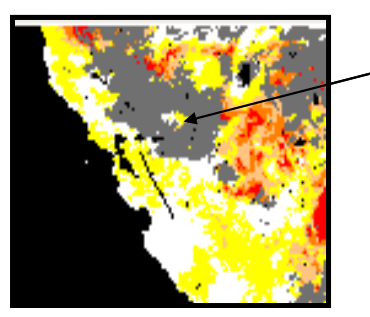

Oct 28, 2007

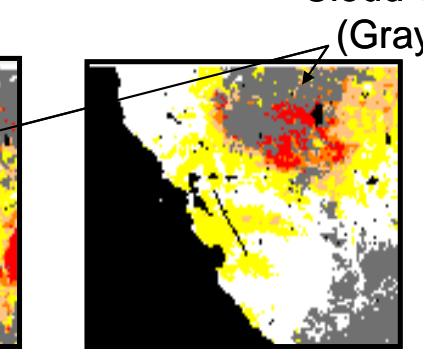

Oct 29, 2007

$+0.2447$

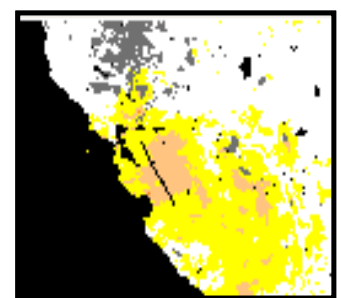

Oct 17, 2007

$+0.3616$

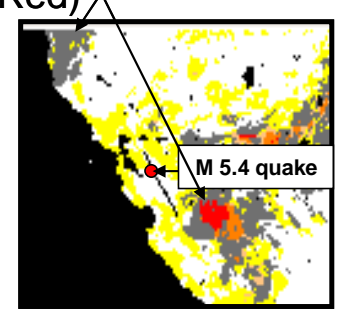

Oct 30, 2007
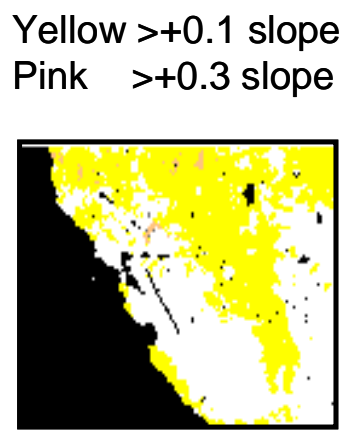

Oct 18, 2007

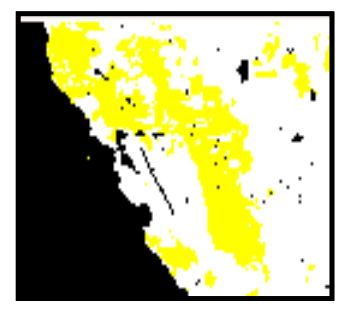

Oct 31, 2007

$-0.0584$

Fig. 20. IR night time temperature slopes, October 2007 Northern California. White=Negative, Yellow and Pink=more positive, Red is typically contaminated, Grey is cloud covered where no slope can be calculated.

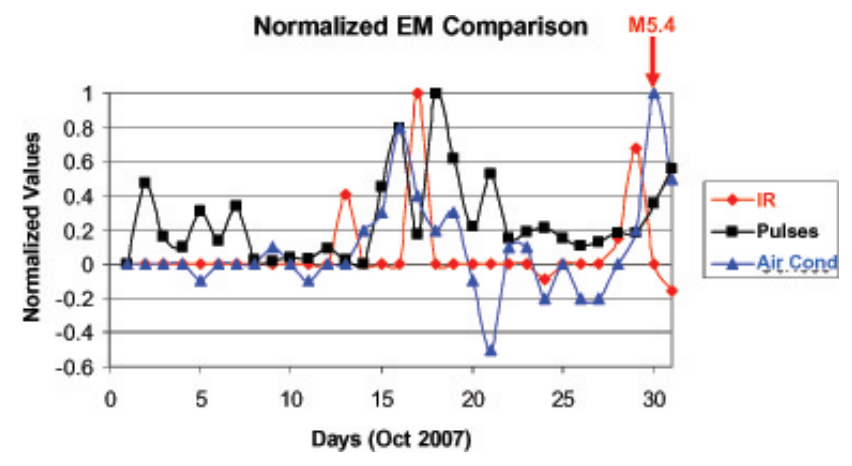

Fig. 21. Comparison of 3 electromagnetic (EM) signatures (IR slope, magnetic pulse count, changes in air conductivity) prior to the Alum Rock quake (M5.4 on 30 October 2007).

huge currents at the hypocenter (kilometers from the site), or smaller currents that have migrated to the surface, near (hundreds of meters) to the magnetometer site.

\subsubsection{Air ionization}

Figure 22 (Run \#39) shows that current increases when stress is changed, and demonstrates positive ion currents migrate toward the negatively charged plates. The insets show the set up. The faces of the two pistons were modified by adding two rows of hardened steel bearings, $5 \mathrm{~mm}$ diameter, to act as stress concentrators. As the steel bearings sank into the rock with increasing load, the hydraulic responded, giving rise to the saw-tooth pattern.

Figure 23 (Run \#42) shows negative currents flowing to a positively charged plate. Both figures show the current flowing up to the moment of failure from the rock surface to a $10 \times 20 \mathrm{~cm}$ ion collector plate, biased $+90 \mathrm{~V}$ or $-90 \mathrm{~V}$, through a $1 \mathrm{~cm}$ wide air gap.

What is noteworthy is the positive ion emission always begins after some load is applied to the rock. Before ion emission occurs, there is a build-up of positive surface charge due to the arrival of positive holes at the rock surface. The positive ion current is due to field-ionization of air molecules, probably $\mathrm{O}_{2}$, at the rock surface. The negative ion plus electron emission always begins later, at higher loads. It is due to corona discharges that commences when the positive fields at the rock surface become so strong that the positive air ions are accelerated away from the rock surface to velocities sufficient to impact-ionize neutral gas molecules and thereby initiate a corona discharge. Each corona discharge is accompanied by a light blip (which have also been recorded) and by RF noise. On a larger scale in earthquake zones, these may be related to the "earthquake lights" (Derr, 1973) and strong $\mathrm{RF}$ (KHz to $\mathrm{MHz}$ ) noise detected (Fujinawa, 1990) prior to large earthquakes. 


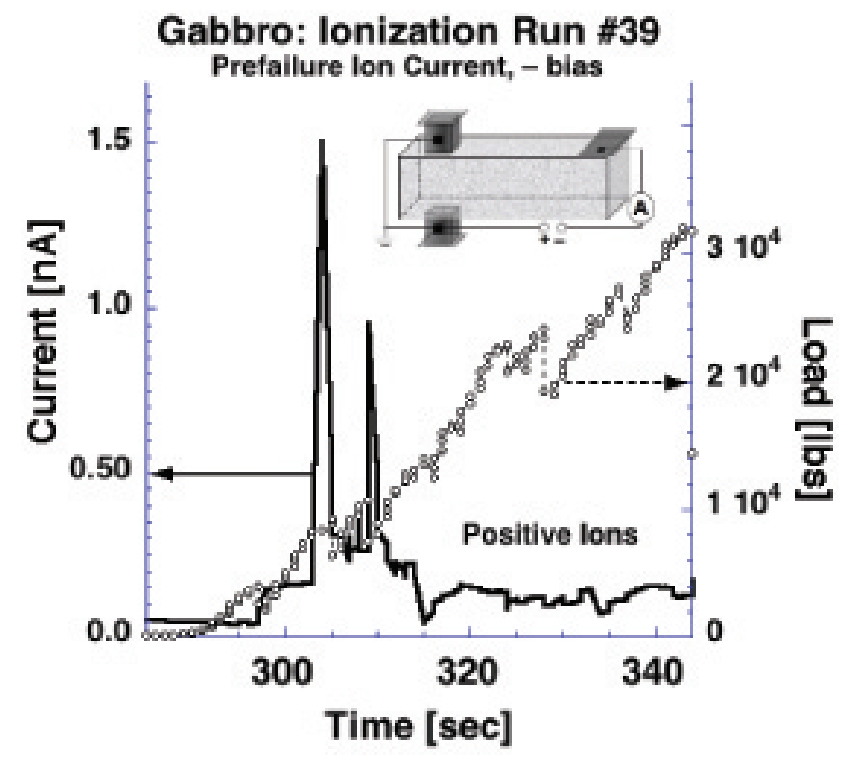

Fig. 22. Laboratory experiment (Freund, 2007a, b, c) showing positive currents after stress is applied.

\subsubsection{Infrared emission}

Additional experiments (Freund, 2007a, b, c) showed IR signatures $(8-12.5 \mu \mathrm{m})$ detected using a Bomem IR spectrometer when this stress was applied. Figure 24 illustrates this effect, and as time progresses and more stress was applied (moving front to back, into the plot), one can see the increasing IR levels, especially in three narrow bands.

There is a natural question whether the laboratory data is indicative of what happens in the actual fault preparation process. Our field data is the first step in correlating these two data sets, and the field data appears to at least support the premise that stress concentration changes, occurring in the days to weeks prior to a medium-large earthquake, may produce underground currents, magnetic field disturbances, air conductivity changes near the epicenter area, and IR apparent heating as manifested in changes in the night time cooling slope near the epicenter region.

\section{Conclusions and future plans}

\subsection{Conclusions}

Each of the 3 EM signature types are summarized below.

\subsubsection{ULF magnetic pulsations}

Large magnetic pulsations were observed to increase in occurrence days prior to the Alum Rock earthquake (October 2007). Since the origin of the observed pulsations was unknown at the time (possibly from man-made noise sources or from the quake area itself), the area around the magnetometer

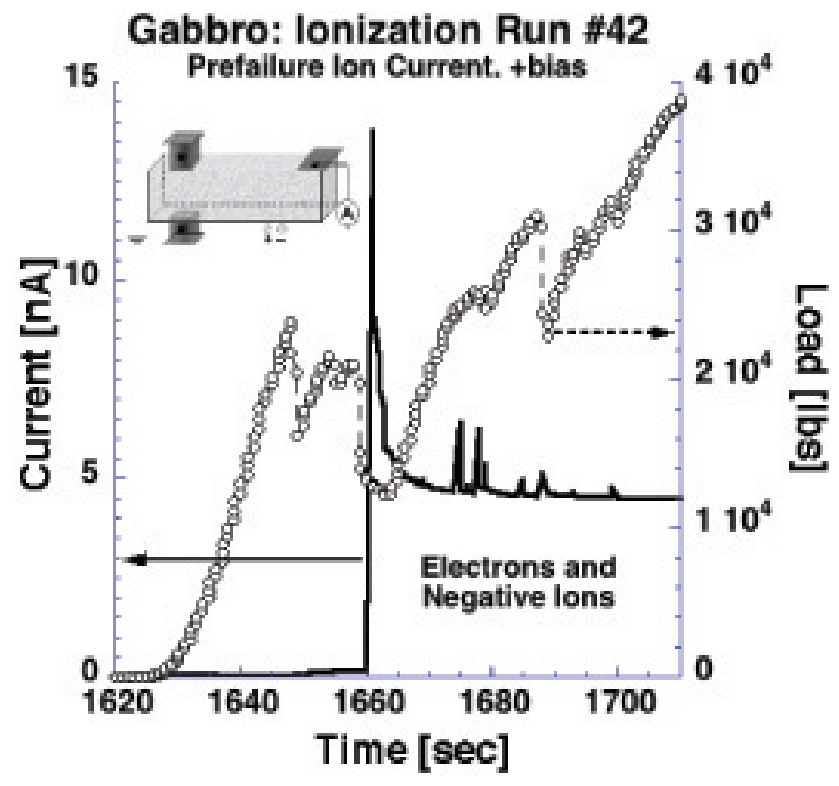

Fig. 23. Laboratory experiment (Freund, 2007a, b, c) showing negative currents after stress is applied.

instrument was surveyed and measured for any similar manmade noise contamination (pulsations from cars, trucks, local machinery, distant high current sources). The largest manmade noise measured was less than $1 \mathrm{nT}$ in amplitude while the pulsations in question frequently exceeded $8-20 \mathrm{nT}$. The instrument itself at the site was also exonerated for possible instrument/power supply/data equipment noise. World wide solar magnetospheric noise e.g. Pc 1, Pc 3, and Pc 4 micro-pulsations were also examined and found to be minimal during the time of the local Alum Rock pulsations. Simultaneous comparisons of the ULF data from the nine other identical instruments, located over the entire State of California were examined, and no simultaneous pulses were found at the time of the strong ULF pulses observed at the quake site instrument, thus eliminating solar/magnetospheric activity as a potential cause. In reviewing all the CalMagNet sites in the network, it was observed that all sites have varying numbers of pulsations every day, depending on the site location. These pulsations may indicate that the fault segments close to these other sites also creep and redistribute stress on a regular basis, but very slowly. This creep and redistribution of stress is a generally accepted concept, especially in a lateral strike slip fault systems. However, when the pulse rate of these unusual unipolar signals increases significantly, AND the rate is sustained for longer than a week, some threshold is exceeded and the earthquake occurs. The 2004 Parkfield M6 quake data contained long time series records, and was also reviewed to see if it behaved in a similar manner. Parkfield, which used magnetometers and data acquisition equipment different from CalMagNet sites, also manifested a pulsation history. The induction magnetometers at Park- 

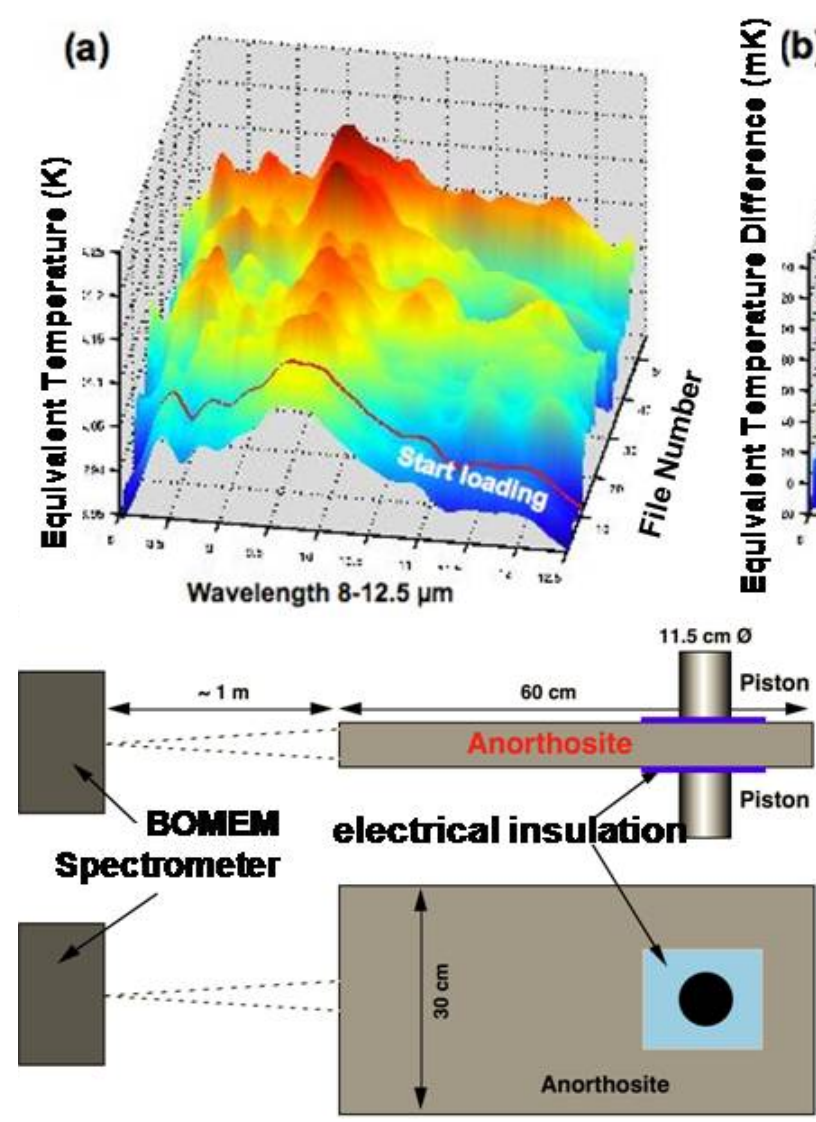

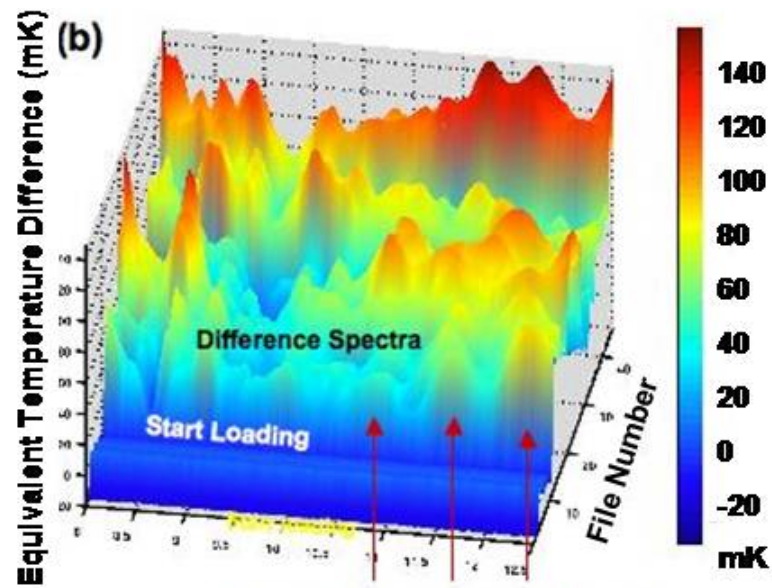

Narrow IR emission bands

\section{IR emission before and during stressing an anorthosite rock $\left(30 \times 60 \times 10 \mathrm{~cm}^{3}\right)$ up to failure.}

Fig. 24. Laboratory experiment (Freund, 2007a, b, c) showing increase in long wave IR after stress is applied.

field specifically exhibited a rise in daily pulse count on the 15 th day prior to the quake. Although the magnitude of the pulsations collected at $19 \mathrm{~km}$ from the epicenter were much smaller than the Alum Rock (M5.4) pulses collected at $2 \mathrm{~km}$ from the epicenter, but this may have been caused by the greater distance between the epicenter and the instrument, and the high conductivity in the NE side of the fault between the epicenter and the instrument.

\subsubsection{Air conductivity}

The air conductivity instrument at the Alum Rock site was examined and showed a large increase in signal (number of ions per $\mathrm{cm}^{3}$ per $\mathrm{s}$ ). The instrument saturated from -20 to $-7 \mathrm{~h}$ prior to the quake, and relative humidity (a contamination source) was relatively low (74\%) during that time, and should not have caused contamination since it was below the instrument's saturation threshold $(95 \% \mathrm{RH})$. Design changes in the sensor have been completed to help eliminate this humidity contamination in the future.

\subsubsection{Infrared}

Infrared signatures from the GOES-West geosynchronous satellite showed an unusual night time temperature slope "heating" effect compared with the 3 year average for the same area/pixels. These positive night time temperature slopes $(>+0.3)$ appeared in an extended area around the quake zone compared with normal negative temperature slopes calculated from the previous 3 years of data. This technique is somewhat hampered by wind-driven, compression heating near mountains (areas where heating slope $>+0.2$ ), but the area around the epicenter exceeded that noise level (slopes greater than +0.3 ) and were correlated with air conductivity and pulse data on the same days. There may need to be some positive threshold limit applied to this IR data to filter out this wind compression heating noise.

\subsubsection{Combined EM comparisons with lab experiments}

ULF pulsations, ion levels, and IR signatures are consistent with the currents, ionization, and IR signatures measured during dynamic stress measurements carried out by Freund in laboratory experiments with igneous rock samples. The primary question was whether the small signals observed in the lab would exist on a larger scale in the field, and would be detectable in the natural, noise-filled environment using a network of sensors that could be compared in space and time with the signals from the quake area. Based on field 
data, it appears that there were some correlating EM signals collected at the Alum Rock and Parkfield areas, and this is a good start. While these two earthquakes do not validate the lab experiments, Alum Rock and Parkfield pulse history and IR data, and Alum Rock air conductivity data do provide some support for the rock stress-electromagnetic signal theory. However, as in any test of a theory, more statistical samples of significant earthquakes (>M5) are needed, and it is increasingly important that this data include calibrated local ULF, air conductivity, and IR measurements to help validate the connection between large earthquakes and these electromagnetic signatures.

\subsection{Future plans}

This team is now adding a pulse counting algorithm for many other CalMagNet instrument sites located throughout California to constantly monitor these signatures and compare them against the local averages to identify similar large pulsations that exceed a threshold level. A more sophisticated "pattern matching" algorithm may be developed in the future to account for the differences in pulse height at longer distances from the epicenter, and to eliminate shorter, lightninggenerated pulses.

We are trying to collaborate with NASA Ames in routinely monitoring IR signatures over California using GOES-West IR data, and then comparing the daily IR results with our CalMagNet data. We hope to start this collaboration in 2009.

Other indicators such as ionospheric TEC changes over the earthquake area should also be added to the list of EM indicators for testing, but processing all this TEC satellite and ground-derived data, may be beyond the scope of funding for our team at this time.

Acknowledgements. The authors wish to acknowledge funding for this activity from C. Ford (Stellar Solutions), J. LaBrecque (NASA $\mathrm{Hq}$ Earth Surface and Interior Focus Area), and DHS/FEMA. We are also grateful for the supporting ULF data at PKD (Parkfield) from UC Berkeley, and GOES IR imager data from NASA and NOAA.

Edited by: M. Contadakis

Reviewed by: D. McPhee and D. Ouzounov

\section{References}

Bortnik, J., Cutler, J. W., Dunson, C., and Bleier, T.: An automatic wave detection algorithm applied to Pc1 pulsations, J. Geophys. Res., 112, A04204, doi:10.1029/2006JA011900, 2007.

Bortnik, J., Cutler, J. W., Dunson, C., and Bleier, T. E.: The possible statistical relation of Pc1 pulsations to Earthquake occurrence at low latitudes, Ann. Geophys., 26, 2825-2836, 2008a, http://www.ann-geophys.net/26/2825/2008/.

Bortnik, J., Cutler, J. W., Dunson, C., Bleier, T. E., and McPherron, R. L.: Characteristics of low latitude Pc1 pulsations during geomagnetic storms, J. Geophys. Res., 113, A04201, doi:10.1029/2007JA012867, 2008b.
Cutler, J., Bortnik, J., Dunson, C., Doering, J., and Bleier, T.: CalMagNet - an array of search coil magnetometers monitoring ultra low frequency activity in California, Nat. Hazards Earth Syst. Sci., 8, 359-368, 2008, http://www.nat-hazards-earth-syst-sci.net/8/359/2008/.

Derr, J. S.: Earthquake lights: a review of observations and present theories, B. Seismol. Soc. Am., 63, 2177-2187, 1973

Fraser-Smith, A. C., Bernardi, A., McGill, P. R., Ladd, M. E., Helliwell, R. A., and Villard Jr., O. G.: Low-Frequency Magnetic Field Measurements near the Epicenter of the Ms 7.1 Loma Prieta Earthquake, Geophys. Res. Lett., 17(9), 14651468, 1990.

Fraser-Smith, A. C., Bernadi, A., McGill, P. R., and Villard Jr., O. G.: ULF magnetic field measurements near the epicenter of the Ms 7.1 Loma Prieta Earthquake, Phys. Earth Planet. In., 68 4563, 1991.

Freund, F. T.: Pre-earthquake signals - Part I: Deviatoric stresses turn rocks into a source of electric currents, Nat. Hazards Earth Syst. Sci., 7, 535-541, 2007a, http://www.nat-hazards-earth-syst-sci.net/7/535/2007/.

Freund, F. T.: Pre-earthquake signals - Part II: Flow of battery currents in the crust, Nat. Hazards Earth Syst. Sci., 7, 543-548, 2007b, http://www.nat-hazards-earth-syst-sci.net/7/543/2007/.

Freund, F. T.: Stimulated IR emission from rocks: Assessing a stress indicator, eEarth, 2, 1-10, 2007c.

Freund, F. T., Takeuchi, A., and Lau, B. W.: Electric currents streaming out of stressed igneous rocks - A step towards understanding pre-earthquake low frequency EM emissions, Phys. Chem. Earth, 31, 389-396, 2006.

Fujinawa, Y. and Takahashi, K.: Emission of electromagnetic radiation preceding the Ito seismic swarm of 1989, Nature, 347, 376-378, 1990.

Liu, J. Y., Chen, Y. I., Chuo, Y. J., and Tsai, H. F.: Variations of ionospheric total electron content during the Chi-Chi earthquake, Geophy. Res. Lett., 28, 1383-1386, 2001.

Molchanov, O., Schekotov, A., Fedorov, E., Belyaev, G., and Gordeev, E.: Preseismic ULF electromagnetic effect from observation at Kamchatka, Nat. Hazards Earth Syst. Sci., 3, 203-209, 2003,

http://www.nat-hazards-earth-syst-sci.net/3/203/2003/.

Molchanov, O., Fedorov, E., Schekotov, A., Gordeev, E., Chebrov, V., Surkov, V., Rozhnoi, A., Andreevsky, S., Iudin, D., Yunga, S., Lutikov, A., Hayakawa, M., and Biagi, P. F.: Lithosphereatmosphere-ionosphere coupling as governing mechanism for preseismic short-term events in atmosphere and ionosphere, Nat. Hazards Earth Syst. Sci., 4, 757-767, 2004, http://www.nat-hazards-earth-syst-sci.net/4/757/2004/.

Ouzounov, D., Liu, D., Kang, C., et al.: Outgoing long wave radiation variability from IR satellite data prior to major earthquakes, Tectonophysics, 431, 211-220, 2007.

Pulinets, S. and Boyarchuk, K.: Ionospheric Precursors of Earthquakes, Springer Verlag, 350 pp., 2004.

Unsworth, M., Bedrosian, P., Eisel, M., Egnert, G., and Siripunvaraporn, W.: Along strike variations in the electrical structure of the San Andreas Fault at Parkfield, California, Geophys. Res. Lett., 27, 3021-3024, 2000.

Yen, H. Y., Chen, C. H., and Liu, J. Y.: Geomagnetic fluctuations during the 1999 Chi-Chi earthquake in Taiwan, Earth Planets Space, 56, 39-45, 2004. 